\title{
Structure and drug binding of the SARS-CoV-2 envelope protein transmembrane domain in lipid bilayers
}

\author{
Venkata S. Mandala $\mathbb{1}^{1}$, Matthew J. McKay ${ }^{\circledR}$, Alexander A. Shcherbakov ${ }^{1}{ }^{1}$, Aurelio J. Dregni', \\ Antonios Kolocouris ${ }^{2}$ and Mei Hong ${ }^{1 \times}$
}

An essential protein of the SARS-CoV-2 virus, the envelope protein E, forms a homopentameric cation channel that is important for virus pathogenicity. Here we report a 2.1- $\AA$ structure and the drug-binding site of E's transmembrane domain (ETM), determined using solid-state NMR spectroscopy. In lipid bilayers that mimic the endoplasmic reticulum-Golgi intermediate compartment (ERGIC) membrane, ETM forms a five-helix bundle surrounding a narrow pore. The protein deviates from the ideal $\alpha$-helical geometry due to three phenylalanine residues, which stack within each helix and between helices. Together with valine and leucine interdigitation, these cause a dehydrated pore compared with the viroporins of influenza viruses and HIV. Hexamethylene amiloride binds the polar amino-terminal lumen, whereas acidic pH affects the carboxy-terminal conformation. Thus, the $\mathbf{N}$ - and $\mathbf{C}$-terminal halves of this bipartite channel may interact with other viral and host proteins semi-independently. The structure sets the stage for designing $E$ inhibitors as antiviral drugs.

E ght months into the COVID-19 pandemic, no vaccines or antiviral drugs are available against the severe acute respiratory syndrome coronavirus 2 (SARS-CoV-2), the causative agent of the pandemic, owing to a lack of knowledge about the detailed structures and functions of the essential virus proteins. The RNA genome of SARS-CoV-2 encodes three membrane proteins (Fig. 1a): the spike protein, which binds the cell-surface receptor to mediate virus entry; the membrane protein, which contributes to virus assembly and budding ${ }^{1}$; and the envelope protein $\mathrm{E}$. $\mathrm{E}$ is a 75-residue viroporin (Fig. 1b) that forms a cation-selective channel across the ERGIC membrane ${ }^{2,3}$. In SARS-CoV-1, E mediates the budding and release of progeny viruses ${ }^{4}$ and activates the host inflammasome ${ }^{5}$. E's channel activity is blocked by hexamethylene amiloride (HMA) ${ }^{6}$ and amantadine (AMT) ${ }^{7}$; the latter also inhibits the viroporins of influenza A virus and HIV-1 (refs. ${ }^{8,9}$ ). E deletion gives rise to attenuated viruses in some coronaviruses ${ }^{10-12}$, whereas E mutations that abolish channel activity cause reduced virus pathogenicity. ${ }^{12}$ Thus $\mathrm{E}$ is a potential antiviral drug target and vaccine candidate against SARS-CoV-2.

Despite its importance to SARS-CoV-2 pathogenesis, E's high-resolution structure, particularly for the ion-conducting transmembrane (TM) domain (residues 8-38) (Fig. 1b) ${ }^{2,3}$, has been elusive. Sedimentation equilibrium and gel-electrophoresis data for the homologous SARS-CoV-1 E indicate that the TM domain assembles into a homopentamer in detergents such as sodium dodecyl sulfate (SDS) and perfluorooctanoic acid ${ }^{6,13,14}$. Although early X-ray scattering data have suggested a helical hairpin model for $\mathrm{E}^{15}$, subsequent solution NMR studies of $\mathrm{E}$ bound to several detergent micelles, including dodecylphosphocholine (DPC) ${ }^{10}, \mathrm{SDS}^{6}$ and lyso-myristoylphosphatidylglycerol (LMPG) ${ }^{16}$, consistently indicate a single-span TM helix. However, the pore-facing residues and the pentameric assembly are not well-established. Fourier-transform infrared dichroic data suggest that the ETM helix orientation in lipid bilayers may be sensitive to the presence or absence of charged residues at the two termini of the TM domain, and by inference, the membrane surface charge ${ }^{17,18}$.

Here, we use solid-state NMR to determine the structure of the SARS-CoV-2 ETM structure in phospholipid bilayers, to avoid potential structural distortion caused by detergents. The structure sets the stage for the design of $\mathrm{E}$ inhibitors as antiviral drugs.

\section{Results}

Backbone conformation of ETM in lipid bilayers. We reconstituted ETM into an ERGIC-mimetic lipid bilayer containing phosphatidylcholine, phosphatidylethanolamine, phosphatidylinositol, phosphatidylserine and cholesterol. For comparison, we also incorporated the protein into a dimyristoylphosphocholine (DMPC): dimyristoylphosphoglycerol (DMPG) model membrane, abbreviated as DMPX below. ETM was expressed in Escherichia coli using a hexahistidine $\left(\mathrm{His}_{6}\right)$-small ubiquitin-like modifier (SUMO) fusion tag and purified first by nickel affinity column chromatography and then by reverse-phase HPLC after cleavage of the solubility tag (Extended Data Fig. 1).

One-dimensional (1D) ${ }^{13} \mathrm{C}$ and ${ }^{15} \mathrm{~N}$ NMR spectra of the protein in ERGIC and DMPX membranes show temperature-insensitive high intensities (Extended Data Fig. 2a,b), indicating that the protein is immobilized in lipid bilayers at ambient temperature. Two-dimensional (2D) ${ }^{15} \mathrm{~N}-{ }^{13} \mathrm{C}$ and ${ }^{13} \mathrm{C}-{ }^{13} \mathrm{C}$ correlation spectra show well-resolved peaks (Fig. $1 \mathrm{c}, \mathrm{d}$ ), with ${ }^{13} \mathrm{C}$ and ${ }^{15} \mathrm{~N}$ linewidths of $0.5 \mathrm{ppm}$ and $0.9 \mathrm{ppm}$, indicating that the protein conformation is highly homogeneous. We assigned the chemical shifts using three-dimensional (3D) correlation NMR experiments (Extended Data Fig. 3a). These chemical shifts indicate that residues 14-34 form the $\alpha$-helical core of the TM domain (Extended Data Fig. 3b,c and Supplementary Table 1). Comparison of spectra between the two membranes and at different temperatures (Extended Data Fig. 2d-f) 


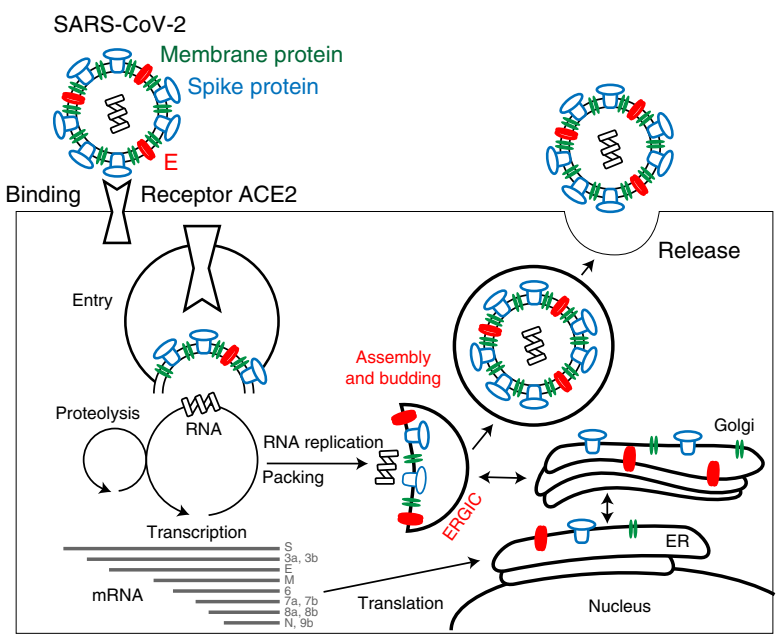

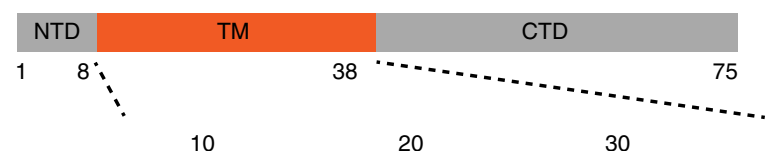

SARS-CoV-2 EET GTLIVNSVLL FLAFVVFLLV TLAILTALR SARS-COV EET GTLIVNSVIL FLAFVVELLV TLAILTALR MERS-COV ERI GLFIVNFFIF TVVCAITLLV CMAFLTATR $\alpha$ HCOV-HKU1 NDT AWYIGQILVL VLFCLISLIF VVAFLATIK HCoV-OC43 ADT VWYVGQIIFI VAICLLVTIV VVAFLATFK HCoV-NL63 DDN G-IVLNSILW LLVMIFFFVI AMTFIKLIQ HCoV-229E DDH A-LVVNVLLW CVVLIVILLV CITIIKLIK
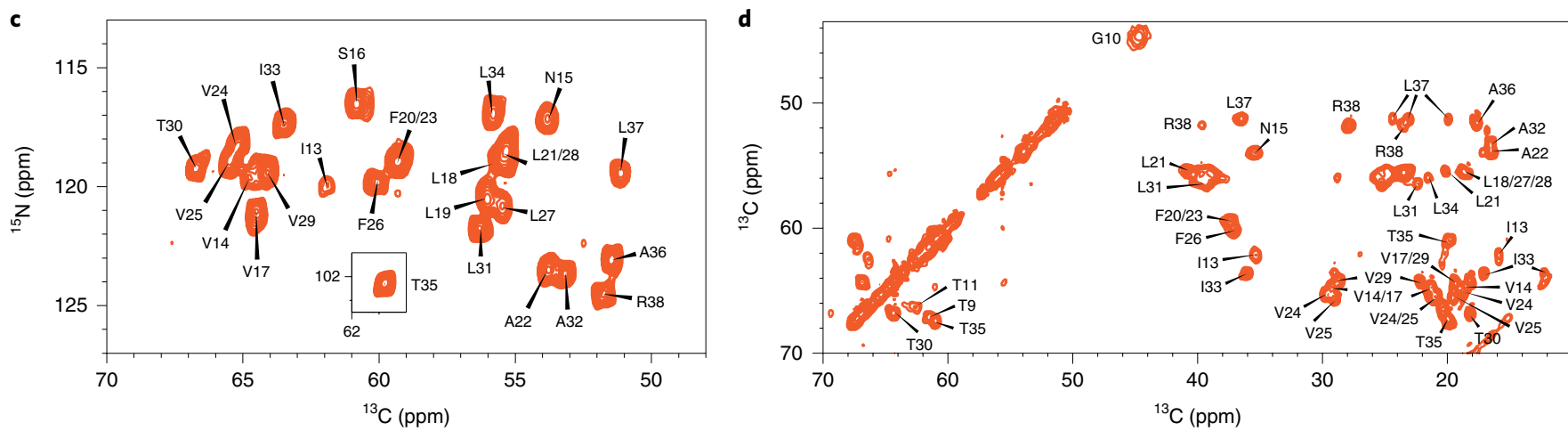

Fig. 1 | Function, amino acid sequence and fingerprint NMR spectra of the SARS-CoV-2 E protein. a, E forms a cation-selective ion channel and mediates SARS-CoV-2 budding and release from the host cell's ERGIC lumen. b. Domain architecture of E and sequence alignment of E's transmembrane segment among several human-infecting coronaviruses. Highly conserved polar residues are shown in red. CTD, C-terminal domain; NTD, N-terminal domain. c,d, 2D ${ }^{15} \mathrm{~N}-{ }^{13} \mathrm{C} \alpha$ correlation spectrum (c) and $2 \mathrm{D}{ }^{13} \mathrm{C}-{ }^{13} \mathrm{C}$ correlation spectrum (d) of ERGIC-membrane-bound ETM. The spectra, measured at ambient temperature, show high sensitivity and resolution, indicating that ETM is structurally homogeneous in lipid bilayers.

indicate that the N-terminal segment (residues Glu8-Ile13) is dynamic at high temperature but is mostly $\alpha$-helical, whereas the C-terminal segment (residues Thr35-Arg38) is more rigid but displays temperature-dependent conformations. Acidic $\mathrm{pH}$ perturbed the chemical shifts of C-terminal residues Leu34 to Arg38 (Extended Data Fig. 4), supporting the conclusion that the $\mathrm{C}$ terminus is conformationally plastic.

Oligomeric structure and hydration of ETM. The overall temperature insensitivity of the protein spectra suggests that ETM is oligomerized in lipid bilayers. To determine the oligomeric structure, we prepared two mixed labeled samples to measure intermolecular contacts. An equimolar mixture of ${ }^{13} \mathrm{C}$-labeled protein and $4-{ }^{19} \mathrm{~F}$-Phe-labeled protein (Extended Data Fig. 1e) was used to measure intermolecular ${ }^{13} \mathrm{C}-{ }^{19} \mathrm{~F}$ distances using the rotational-echo double-resonance (REDOR) technique ${ }^{19}$ (Fig. 2a). ETM contains three regularly spaced Phe residues, Phe20, Phe23 and Phe26, at the center of the TM segment. $1 \mathrm{D}$ and $2 \mathrm{D}{ }^{13} \mathrm{C}$ NMR spectra were measured without and with ${ }^{19} \mathrm{~F}$ pulses. The resulting difference spectra show the signals of carbons that are in close proximity to a fluorinated Phe on a neighboring helix (Fig. $2 \mathrm{~b}$ and Extended Data Fig. 5a-c). As expected, residues Val17 to Leu31 are affected by $4-{ }^{19} \mathrm{~F}-\mathrm{Phe}$, while residues Ile13 to Ser16 and Ala36 to Arg38 show no REDOR dephasing. Moreover, the three Phe residues display 2 resolved ${ }^{19} \mathrm{~F}$ chemical shifts with a roughly $2: 1$ intensity ratio, indicating that one of the residues has a distinct side chain conformation. A $2 \mathrm{D}{ }^{13} \mathrm{C}-{ }^{19} \mathrm{~F}$ correlation spectrum (Fig. 2c) shows a cross-peak between the $-118 \mathrm{ppm}{ }^{19} \mathrm{~F}$ signal and Ala22 $\mathrm{C} \beta$, indicating that this -118 ppm peak is due to either Phe20 or Phe23. The $-113 \mathrm{ppm}{ }^{19} \mathrm{~F}$ peak shows strong cross-peaks with aromatic and numerous aliphatic ${ }^{13} \mathrm{C}$ chemical shifts. Since Phe20 and Phe26 are too far away from each other to form intermolecular contacts, the $-118 \mathrm{ppm}{ }^{19} \mathrm{~F}$ peak must be assigned to Phe20, while the -113 ppm peak must be assigned to Phe23 and Phe26. To constrain the interhelical packing at the two termini of the TM domain, we prepared a sample with mixed ${ }^{13} \mathrm{C}$ and ${ }^{15} \mathrm{~N}$ labels and measured $2 \mathrm{D}$ NHHC correlation spectra to identify exclusively intermolecular ${ }^{15} \mathrm{~N}-{ }^{13} \mathrm{C}$ correlations (Fig. $2 \mathrm{~d}$ ). These experiments together yielded 35 interhelical ${ }^{13} \mathrm{C}-{ }^{19} \mathrm{~F}$ distance restraints and 52 interhelical ${ }^{15} \mathrm{~N}-{ }^{13} \mathrm{C}$ correlations, which are crucial for determining the oligomeric structure of ETM.

To further constrain the architecture of ETM self-assembly, we measured residue-specific water accessibilities using water-edited $2 \mathrm{D}{ }^{15} \mathrm{~N}-{ }^{13} \mathrm{C}$ correlation experiments (Fig. 2e and Extended Data Fig. $5 \mathrm{~d})^{20,21}$. Water ${ }^{1} \mathrm{H}$ magnetization transfer is the highest to the $\mathrm{N}$-terminal residues, is the least to the central residues Leu17 to Ala32 and is moderate to the $\mathrm{C}$ terminus (Fig. 2f). Thus, the hydration gradient of the protein is primarily along the bilayer normal. The preferential hydration of the $\mathrm{N}$ terminus is especially manifested by the high water-transferred intensity of Leu19 compared with that of Thr30, despite favorable chemical exchange to the Thr side chain ${ }^{22-24}$. For the dehydrated center of the TM domain, 
a

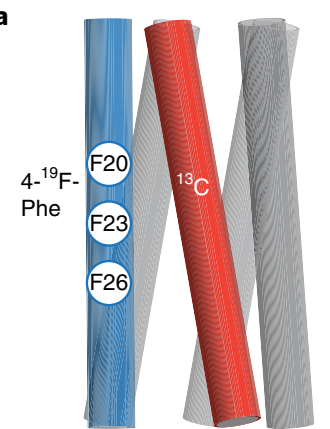

b

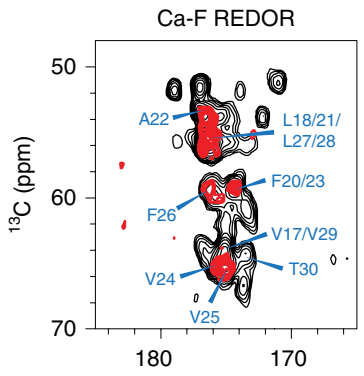

$10.3 \mathrm{~ms}, \mathrm{~S}_{0}, \Delta \mathrm{S}$

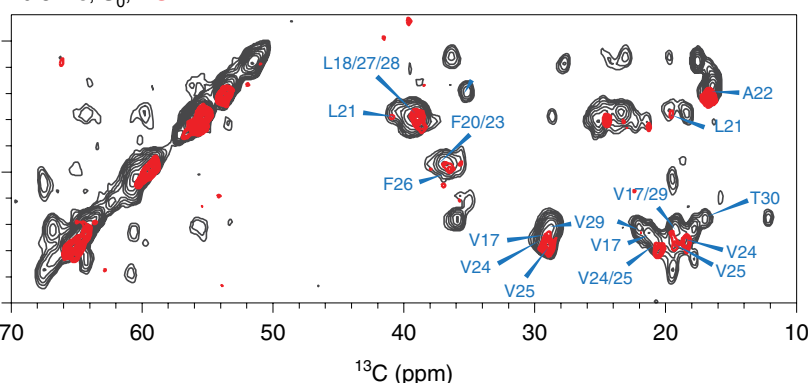

C
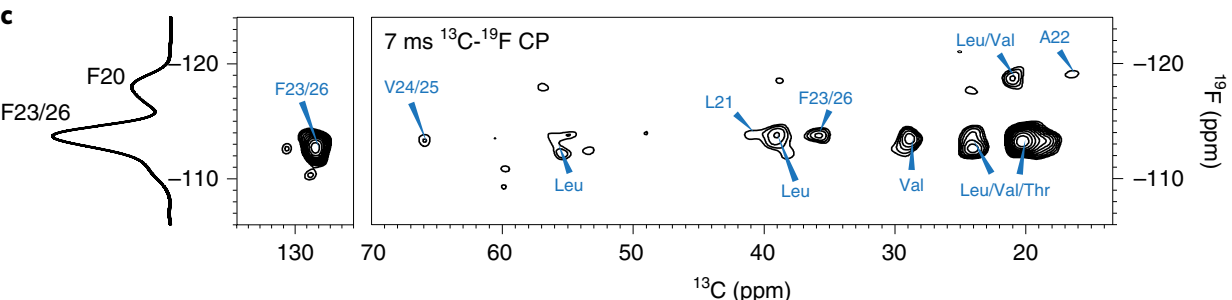

d

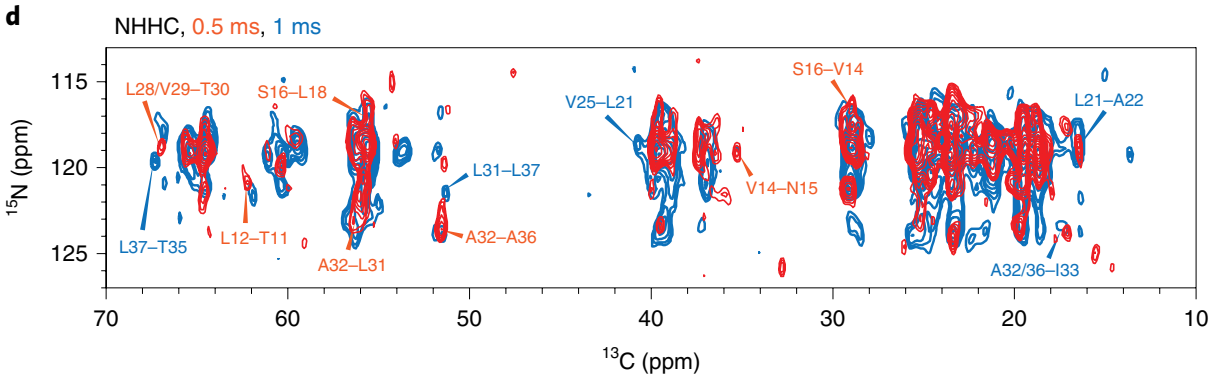

e

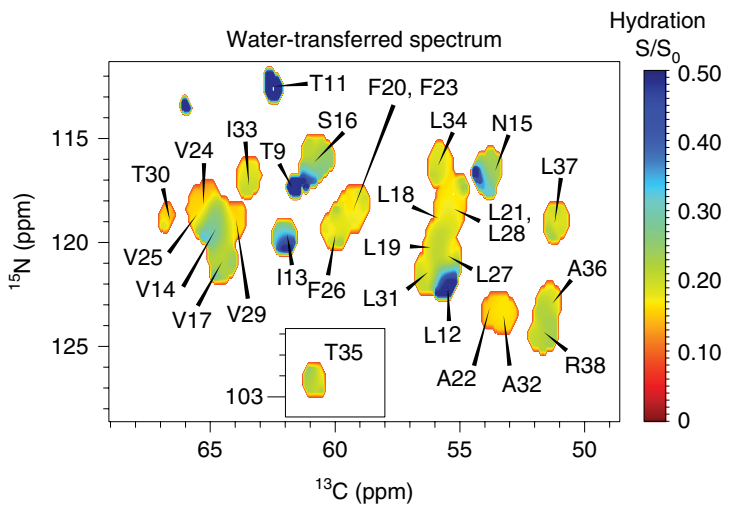

f

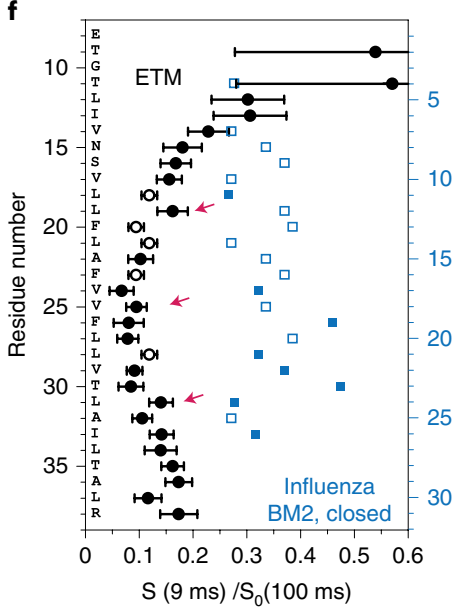

g

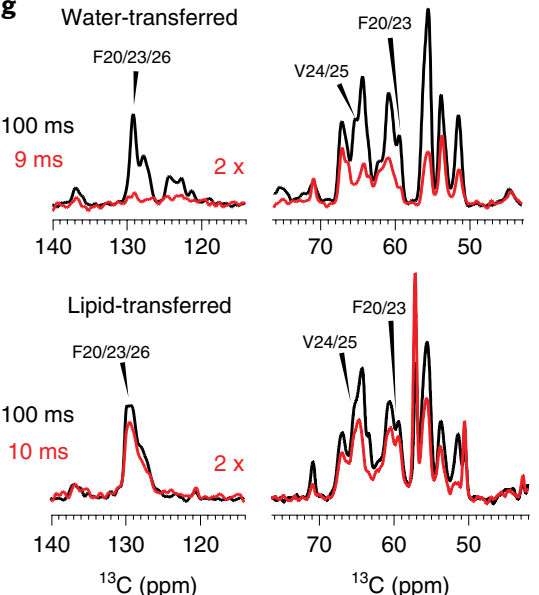

Fig. 2 | Measurement of interhelical distances and water accessibility of membrane-bound ETM. a, Schematic of mixed $\left[{ }^{19} \mathrm{~F}\right] \mathrm{ETM}$ and $\left[{ }^{13} \mathrm{C}\right] \mathrm{ETM}$ in a five-helix bundle. $\mathbf{b}, 2 \mathrm{D}{ }^{13} \mathrm{C} \alpha-\mathrm{F}$ REDOR spectra of ERGIC-membrane-bound ETM. The control spectrum ( $\mathrm{S}_{0}$, black) shows the signals of all residues, whereas the difference spectrum $\left(\Delta \mathrm{S}\right.$, red) shows the signals of residues that are close to fluorinated Phe on a neighboring helix. $\mathbf{c}, 2 \mathrm{D}{ }^{13} \mathrm{C}-{ }^{19} \mathrm{~F}$ correlation spectrum allows assignment of the -118 ppm peak to Phe20 due to a cross-peak with Ala22, whereas the -113 ppm peak is assigned to Phe23 and Phe26 on the basis of correlations with Phe23 and Phe26 and with Val24 and Val25. A 1D ${ }^{1} \mathrm{H}^{-19} \mathrm{~F}$ cross-polarization (CP) spectrum is shown on the left. d, 2D $\mathrm{NHHC}$ correlation spectrum of mixed $\left[{ }^{13} \mathrm{C}\right]$ ETM and $\left[{ }^{15} \mathrm{~N}\right] \mathrm{ETM}$, measured using $0.5 \mathrm{~ms}$ (red) and $1 \mathrm{~ms}$ (black) ${ }^{1} \mathrm{H}$ mixing. All peaks arise from interhelical contacts. Selected assignments are given. e, Residue-specific water accessibilities of ERGIC-bound ETM obtained from the intensity ratios of water-edited spectra measured with $9 \mathrm{~ms}$ and $100 \mathrm{~ms}^{1} \mathrm{H}$ mixing. Higher values (blue) indicate greater water accessibility. f, Water-edited intensities of ETM (black) and influenza BM2 (blue) obtained as the peak intensity ratios of the 9-ms and 100-ms spectra. Closed and open symbols indicate resolved and overlapped peaks, respectively. Error bars indicate the random uncertainty, which is propagated from the signal-to-noise ratios of the two spectra. ETM shows lower water-edited intensities than does BM2, indicating that the ETM pore is drier than the closed BM2 pore. g, Water-and lipid-edited ${ }^{13} \mathrm{C}$ spectra of membrane-bound ETM. The Phe signals are high in the lipid-edited spectra but very low in the water-edited spectra, indicating that the three Phe residues are poorly hydrated and point to the lipids or the helix-helix interface. 
Table 1 | NMR and refinement statistics

SARS-CoV-2 ETM

(BMRB 30795, PDB 7K3G)

\begin{tabular}{ll}
\hline NMR distance and dihedral constraints & \\
\hline Distance constraints & \\
\hline Total NOE & $283 \times 5$ \\
\hline Inter-residue & $283 \times 4$ \\
\hline Sequential $(|i-j|=1)$ & $125 \times 5$ \\
\hline Medium range $(2 \leq|i-j| \leq 4)$ & $71 \times 5$ \\
\hline Long range $(|i-j| \geq 5)$ & $0 \times 5$ \\
\hline Intermolecular & $87 \times 5$ \\
\hline Hydrogen bonds & $11 \times 5$ \\
\hline Total dihedral-angle restraints & \\
\hline$\phi$ & $28 \times 5$ \\
\hline$\psi$ & $28 \times 5$ \\
\hline Structure statistics & \\
\hline Violations (mean \pm s.d.) & \\
\hline Distance constraints $(\AA)$ & $0.17 \pm 0.06$ \\
\hline Dihedral-angle constraints $\left(^{\circ}\right)$ & $0.68 \pm 0.34$ \\
\hline Max dihedral-angle violation $\left(^{\circ}\right)$ & 5.54 \\
\hline Max distance-constraint violation $(\AA)$ & 1.74 \\
\hline Deviations from idealized geometry & \\
\hline Bond lengths $(\AA)$ & $0.004 \pm 0.001$ \\
\hline Bond angles $\left(^{\circ}\right)$ & $0.54 \pm 0.06$ \\
\hline Impropers $\left({ }^{\circ}\right)$ & $0.42 \pm 0.04$ \\
\hline Average pairwise r.m.s.d. $(\AA){ }^{a}$ & $2.06 \pm 0.58$ \\
\hline Heavy & $1.67 \pm 0.65$ \\
\hline Backbone & \\
\hline
\end{tabular}

aPairwise r.m.s.d. was calculated among the ten lowest-energy refined structures.

Leu28 and Val25 show higher hydration than do their neighboring residues, suggesting that these two residues face the pore. A complementary lipid-edited experiment (Fig. 2g) showed much higher intensities for the Phe side chain carbons than their corresponding water-transferred intensities, indicating that the Phe residues are largely lipid-facing. The ERGIC-bound ETM shows twofold lower water accessibility than that of the closed state of the influenza BM2 at the same $\mathrm{pH}^{25}$ (Fig. 2f).

Structure calculation of ETM in ERGIC membranes. We calculated the structure of ETM using the above $56(\phi, \psi)$ torsion angles, 87 interhelical distance restraints (Supplementary Tables 2 and 3) and 196 intrahelical ${ }^{13} \mathrm{C}-{ }^{13} \mathrm{C}$ contacts obtained from $250-\mathrm{ms} 2 \mathrm{D}$ ${ }^{13} \mathrm{C}$ spin diffusion spectra (Extended Data Fig. 6) ${ }^{26}$. Initial calculation using directionally ambiguous interhelical contacts where the observed helix is assumed to contact either of the two neighboring helices did not converge. Since previously reported micelle-bound ETM structures show substantial variations in pore residue identities and handedness of the helical bundle, we evaluated various pentamer packing models (Extended Data Fig. 7 and Supplementary Table 4) for their agreement with experimentally measured constraints, including the water and lipid accessibilities, interhelical Phe-Phe contact in the ${ }^{13} \mathrm{C}-{ }^{19} \mathrm{~F}$ REDOR data and ${ }^{13} \mathrm{C}$ secondary chemical shifts. A single pentamer model, characterized by having Asn15 and Val25 at similar pore-facing orientations and all three Phe residues facing lipids, was found to best describe the experimental data. This model was subsequently used to disambiguate the direction of interhelical contacts.

The lowest-energy structure ensemble, calculated using XPLOR-NIH (Supplementary Table 5 and Table 1), shows a long and tight 5-helix bundle with a vertical length of $\sim 35 \AA$ for residues Val14-Leu34. The structure resolution is higher for the middle of the TM domain, where ${ }^{13} \mathrm{C}-{ }^{19} \mathrm{~F}$ REDOR distance restraints are available, and lower for the two termini, where fewer distance restraints are available (Fig. 3a and Extended Data Fig. 8a,b). The side chain rotamers are not precisely defined, especially for side chains well away from the central three Phe residues (Extended Data Fig. 8b). The channel diameter, represented by backbone $\mathrm{C} \alpha-\mathrm{C} \alpha$ distances between helices $i$ and $i+2$ for pore-facing residues, varies from $11 \AA$ to $14 \AA$. The helix is tilted by a small angle of $5-10^{\circ}$ from the bilayer normal (Fig. $3 b$ ), but the orientation is not uniform along the length of the peptide, because the helix is non-ideal but exhibits a rotation angle change, or twist, between residues Phe20 and Phe23 (refs. ${ }^{10,16}$ ). Consistent with the small tilt angle, the helical bundle does not display a strong handedness. The pore of the channel is occupied by predominantly hydrophobic residues, including Asn15, Leu18, Leu21, Val25, Leu28, Ala32 and Thr35 (Fig. 3b,c and Extended Data Fig. 8a,b), explaining the poor hydration of the protein. The N-terminal pore is constricted by Asn15, which forms interhelical side chain hydrogen bonds (Fig. $3 \mathrm{~g})^{27}$. The pore-facing positions of Asn 15 and Val25 are consistent with single-channel conductance data showing that p.N15A and p.V25F abolish cation conductance $^{3,7}$. The helix-helix interface is stabilized by aromatic stacking of Phe23 and Phe26 (Fig. 3e,g) and van der Waals packing among methyl-rich resides such as the Val29-Leu31-Ile33 triad (Fig. 3f). These extensive hydrophobic interactions give rise to a tighter helical bundle than do the viroporins influenza BM2 and HIV-1 Vpu (Extended Data Fig. 8d).

ETM interactions with hexamethylene amiloride and amantadine. To investigate how ETM interacts with drugs, we measured the chemical shifts of the protein in the presence of HMA and $\left[3-{ }^{19} \mathrm{~F}\right]$ amantadine. At a drug:protein molar ratio of 4:1, HMA caused significant chemical shift perturbations (CSPs) to N-terminal residues, including Thr9, Gly10, Thr11, Ile13 and Ser16, followed by more modest CSPs for the C-terminal Ala36 and Leu37 (Fig. 4a-c). This trend is consistent with the micelle data ${ }^{10,16}$, but the CSPs in lipid bilayers are much larger, with the $\mathrm{N}$-terminal ${ }^{9} \mathrm{TGT}^{11}$ triplet giving per-residue CSPs of $0.35-0.70 \mathrm{ppm}$. Moreover, the CSPs in lipid bilayers were measured under only fourfold drug excess, while in micelles, the smaller CSPs were measured under higher drug excesses of 10 - to 31 -fold ${ }^{10,16}$.

The higher sensitivity of ETM to HMA in lipid bilayers strongly suggests that the bilayer-bound protein conformation is more native. A docking pose based on these CSPs found that HMA intercalates shallowly into the N-terminal lumen with a distribution of orientations (Fig. 4d and Extended Data Fig. 9), suggesting a dynamic binding mode wherein HMA exchanges between multiple helices and inhibits cation conduction by steric occlusion of the pore. Within the ensemble of docked structures, more HMA molecules point the guanidinium into the pore and the hexamethylene ring towards the lipid headgroups than in the reverse orientation. AMT caused smaller CSPs than HMA (Fig. 4c and Extended Data Fig. 10a,b), but the binding site remains at the $\mathrm{N}$ terminus. Using the $3-{ }^{19} \mathrm{~F}$ label on adamantane, we measured protein-drug proximities using ${ }^{13} \mathrm{C}-{ }^{19} \mathrm{~F}$ REDOR. The spectra showed modest dephasing for the N-terminal Asn15 and C-terminal Ile33 (Extended Data Fig. 10c-e), in qualitative agreement with the observed CSPs. The CSPs of HMA are larger than those of AMT and are consistent with the stronger affinity of $\mathrm{HMA}^{6}$ than $\mathrm{AMT}^{7}$ for SARS-CoV E, as well as with the micromolar half-maximal effective concentration $\left(\mathrm{EC}_{50}\right)$ reported for HMA against other human coronavirus $\mathrm{E}$ proteins ${ }^{28}$. 
a

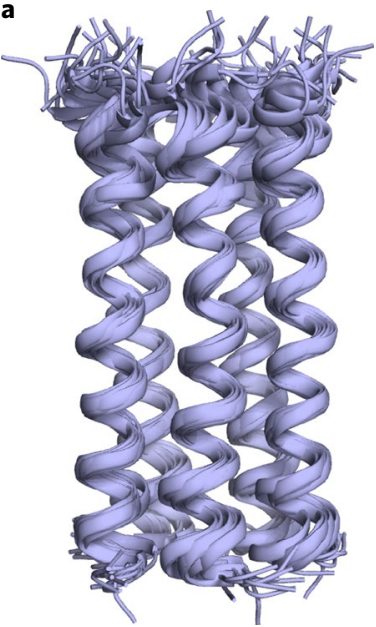

e

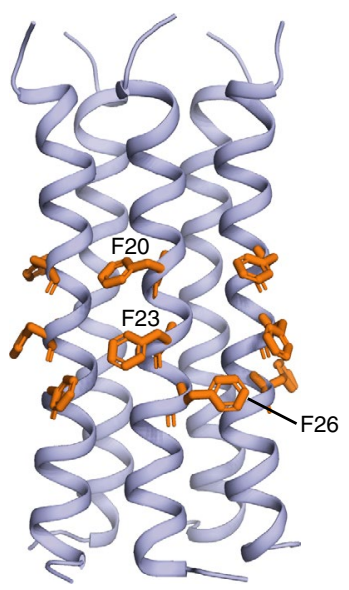

b

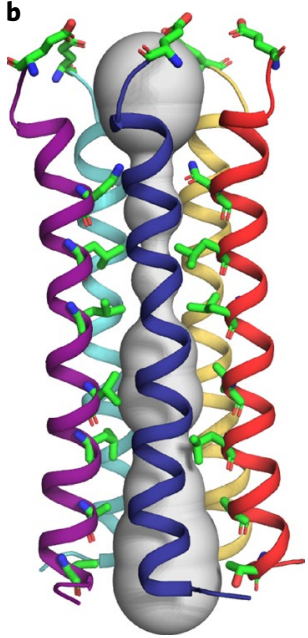

f
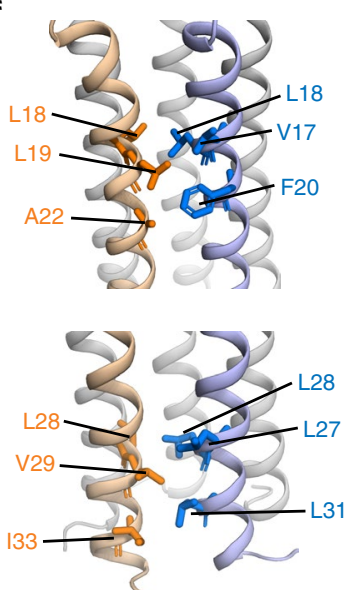
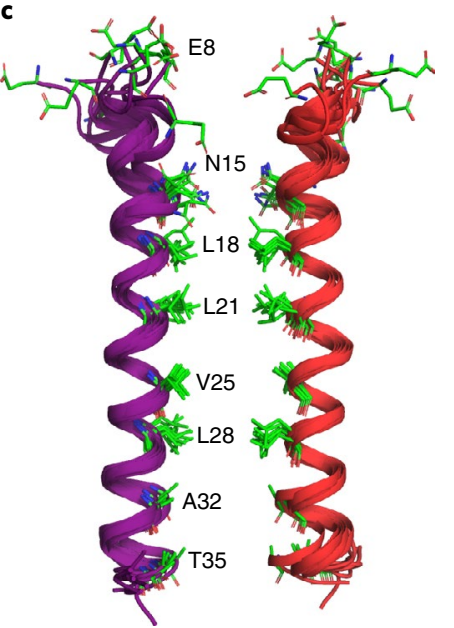

g
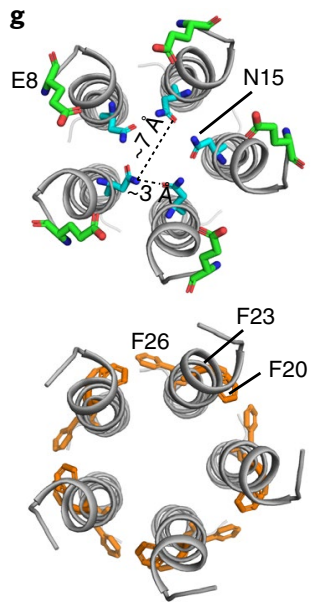

d

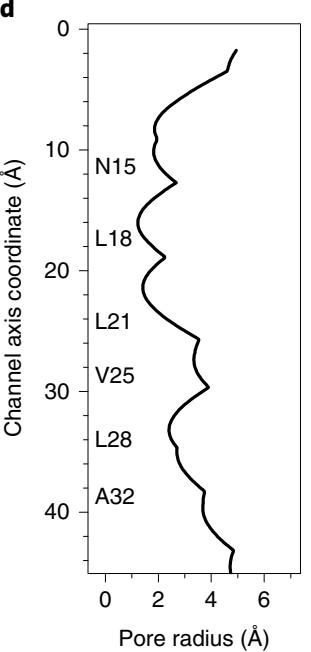

h

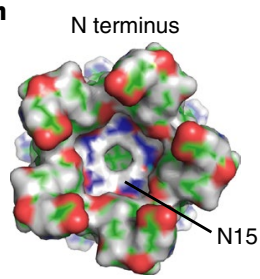

C terminus

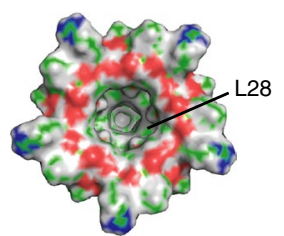

Fig. 3 | Structure of SARS-CoV-2 envelope protein's transmembrane domain in ERGIC-mimetic lipid bilayers. a, Ensemble of ten lowest-energy structures. b, Side view of the most representative structure together with the HOLE-calculated pore water (gray). Pore-lining residues are shown as sticks. c, Simplified two-helix view with the pore-facing residues and their distributions in the lowest-energy ensemble. d, Pore radius of ETM obtained from the HOLE program. e-h, Additional snapshots from the most representative structure. e, Lipid-facing and helix-interface positions of the three Phe residues. $\mathbf{f}$, Two clusters of methyl-interdigitating Leu, Ile and Val residues, stabilizing the helix-helix interface. $\mathbf{g}$, Top views of the $\mathrm{N}$-terminal Glu8, the pore-facing Asn15, and the three Phe residues. h, Surface plots of the pentamer, showing the N-and C-terminal vestibules where Asn 15 and Lys 28 are the first pore-facing residue.

\section{Discussion}

The current lipid-bilayer-based structural model of SARS-CoV-2 ETM has similarities with, but also considerable differences from, micelle-derived structural models (PDB 5X29) ${ }^{16}$. In LMPG micelles, the TM domain of a longer E construct (residues 8-65) also displays a kinked helix and a disordered $\mathrm{N}$ terminus, but the helical bundle is right-handed ${ }^{16}$, and the helices are more tilted and loosely packed (Extended Data Fig. 8c). In comparison, the bilayer-based ETM structural model does not have a strong handedness, consistent with the small helical tilt angle, and both reflect the measured interhelical distance restraints (Supplementary Tables 2 and 3). The heavy-atom r.m.s. deviation (r.m.s.d.) for residues 14-34 between the 2 structural models is $6.1 \AA$, and the positions of various important residues differ. For example, in the LMPG-derived structural model, Phe26 is pore-facing and Thr30 is interhelical ${ }^{16}$, but in the bilayer-derived structure model, both residues point to lipids. The lipid-facing position of Thr30 in the current model is supported by single-channel conductance data showing that mutations of residues such as Thr30 and Thr11 to Ala do not affect the channel activity ${ }^{3}$. Another structural model of ETM determined in DPC micelles ${ }^{10}$ showed a left-handed and coiled helical bundle that differs qualitatively from the LMPG-bound model. These structural differences likely result from a combination of insufficient experimental restraints as well as an inherent conformational plasticity of the ETM. The LMPG-based structural model was obtained from ten unambiguous interhelical distances but no orientational restraints ${ }^{16}$, whereas the DPC-based structural model was built with orientational restraints but no unambiguous interhelical distance restraints ${ }^{10}$. For comparison, the current bilayer-derived ETM structure model was calculated from 87 interhelical distance constraints (Table 1).

Apart from experimental limitations, ETM's oligomeric structure may be intrinsically sensitive to the membrane environment ${ }^{29}$ because the highly hydrophobic nature of the long central portion of the TM segment makes interhelical interactions non-specific. Indeed, SARS-CoV viruses with a p.V25F mutation develop escape mutants p.L27S, p.L19A, p.T30I and p.L37R in mice, implying that E's channel activity is restored by these compensatory double mutations ${ }^{12}$. We speculate this could result from moderate changes of the helix rotation angle to give rise to alternate packing of the helical bundle. Future studies of $\mathrm{E}$ mutants are required to elucidate the structural basis for the loss and restoration of ion-channel activity. 
a

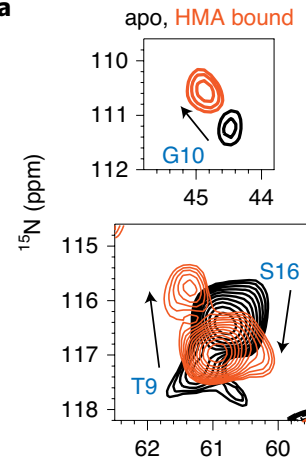

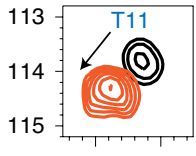

$63 \quad 62$

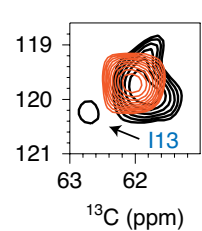

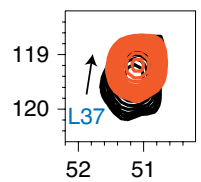

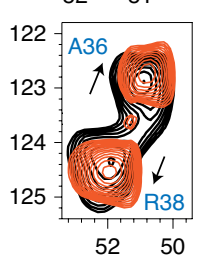

b

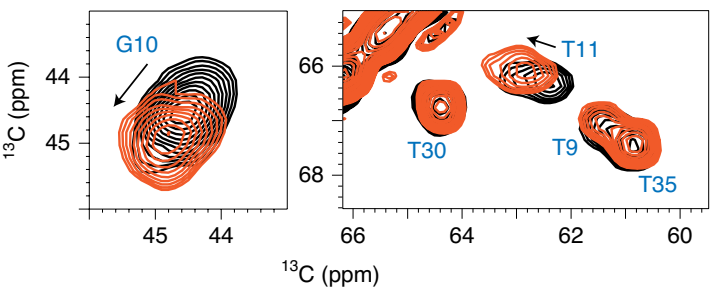

d
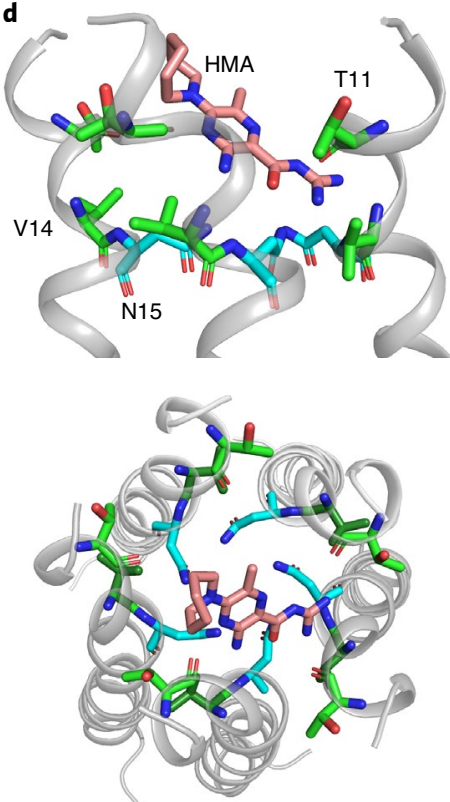

Fig. 4 I Effects of HMA and AMT binding to ETM in DMPC: DMPG membranes. a, 2D ${ }^{15} \mathrm{~N}-{ }^{13} \mathrm{C} \alpha$ correlation spectra of HMA-free (apo, black) and HMA-bound ETM (orange), showing chemical-shift perturbations (CSPs) by HMA. b, $2 \mathrm{D}{ }^{15} \mathrm{~N}-{ }^{13} \mathrm{C} \alpha$ correlation spectra of the apo (black) and HMA-bound ETM (orange). c, Residue-specific CSPs induced by HMA and AMT. N-terminal residues are the most perturbed by the drugs, and HMA causes greater perturbation than AMT. Dashed lines indicate the average CSPs. d, A representative docking pose of HMA. The drug lies in the N-terminal vestibule, with the guanidinium group interacting with polar residues such as Thr11.

How does the SARS-CoV-2 ETM structure compare with the structures of equivalent viroporins of influenza and HIV-1 viruses in lipid bilayers? The ETM helical bundle is compact and rigid, while AM2 and BM2's TM domains, which have a higher percentage of polar residues such as His and Ser, form wider and more hydrated pores (Extended Data Fig. 8d) ${ }^{9,25}$. The HIV-1 Vpu TM domain has a high percentage of hydrophobic residues, similarly to SARS-CoV-2 E, but forms a shorter $(\sim 20 \AA$ vertical length) pentameric helical bundle with more tilted helices $\left(\sim 20^{\circ}\right)^{30,31}$. The ETM helical bundle is more immobilized than M2 and Vpu helical bundles ${ }^{32}$, and does not undergo rigid-body fast uniaxial rotation at high temperatures in DMPX membranes (Extended Data Fig. 2). This immobilization suggests that ETM may interact extensively with lipids ${ }^{3}$. Finally, the helix distortion at residues Phe20-Phe23 may cause the two halves of the protein to respond semi-independently to environmental factors such as $\mathrm{pH}$, charge, membrane composition and other viral and host proteins.

Which structural features of this ETM helical bundle might be responsible for cation conduction? We hypothesize that the $\mathrm{N}$ terminus, which contains a $(\mathrm{E} / \mathrm{D} / \mathrm{R})_{8} \mathrm{X}(\mathrm{G} / \mathrm{A} / \mathrm{V})_{10} \mathrm{XXhh}(\mathrm{N} / \mathrm{Q})_{15}$ motif (Fig. $1 b)$, where $\mathrm{h}$ is a hydrophobic residue, contains the cation selectivity filter. In this conserved motif, the most exposed residue, Glu8, belongs to a dynamic $\mathrm{N}$ terminus whose residues (for example Thr9 and Gly10) manifest intensities only at high temperature (Extended Data Fig. 2d-f). The Glu8 side chain carboxyl is deprotonated at neutral $\mathrm{pH}$ and protonated at acidic $\mathrm{pH}$, as manifested by ${ }^{13} \mathrm{C}$ chemical shifts (Extended Data Fig. 2c). We speculate that the protonation equilibria of this loose ring of Glu8 quintet, together with the anionic lipids in the ERGIC membrane, may regulate the ion selectivity of ETM at the channel entrance. Such a ring of negatively charged Glu residues has been observed as selectivity filters in the hexameric $\mathrm{Ca}^{2+}$-selective Orai channels ${ }^{33}$ and designed $\mathrm{K}^{+}$channels $^{34}$. The third residue of the motif (G/A/V) is conserved among coronaviruses to be small and flexible (Fig. 1b), which might permit $\mathrm{N}$-terminus motion and/or prevent occlusion of the channel lumen. The last residue of the motif is conserved to be either Asn or Gln, whose polar sidechains can coordinate ions and participate in interhelical hydrogen bonds to stabilize the channel ${ }^{27}$. At the C-terminal end of the TM segment, the conserved small residues Ala32 and Thr35 provide an open cavity for ions. In contrast to these small polar residues, the central portion of the TM domain contains four layers of hydrophobic residues, Leu18, Leu21, Val25 and Leu28, which narrow the pore radius to $\sim 2 \AA$ (Fig. 3 d). This narrow pore can permit only a single file of water molecules, thus partially dehydrating any ions that move through the pore. Therefore, the structure determined here may represent the closed state of SARS-CoV-2 E, while the open state might have a larger and more hydrated pore. Narrow pores with multiple hydrophobic layers have also been observed in larger ion channels, including the tetrameric $\mathrm{K}^{+}$channel TMEM175 (ref. ${ }^{35}$ ) and the pentameric bestrophin channels ${ }^{36,37}$. Thus, it is possible to achieve charge stabilization and ion selectivity in such 
a hydrophobic environment, although the detailed mechanisms remain to be understood.

The present membrane-bound ETM structure suggests that small-molecule drugs should have high-affinity binding to both the acidic Glu8 and the polar Asn15 in order to occlude the $\mathrm{N}$-terminal entrance of the protein. The membrane topology of SARS-CoV-2 $\mathrm{E}$ is now recognized to be $\mathrm{N}_{\text {lumen }}-\mathrm{C}_{\text {cyto }}$ on the basis of antibody-detected selective permeabilization assays ${ }^{38}$ and glycosylation data ${ }^{39}$. This orientation may prime the protein to conduct $\mathrm{Ca}^{2+}$ out of the ERGIC lumen to activate the host inflammasome ${ }^{5}$. Thus, small-molecule drugs should ideally be targeted and delivered to the Golgi and ERGIC of host cells to maximally inhibit SARS-CoV-2 E's channel activity ${ }^{40}$.

\section{Online content}

Any methods, additional references, Nature Research reporting summaries, source data, extended data, supplementary information, acknowledgements, peer review information; details of author contributions and competing interests; and statements of data and code availability are available at https://doi.org/10.1038/ s41594-020-00536-8.

Received: 16 September 2020; Accepted: 28 October 2020; Published online: 11 November 2020

\section{References}

1. Weiss, S. R. \& Navas-Martin, S. Coronavirus pathogenesis and the emerging pathogen severe acute respiratory syndrome coronavirus. Microbiol. Mol. Biol. Rev. 69, 635-664 (2005).

2. Wilson, L., McKinlay, C., Gage, P. \& Ewart, G. SARS coronavirus E protein forms cation-selective ion channels. Virology 330, 322-331 (2004).

3. Verdiá-Báguena, C. et al. Coronavirus E protein forms ion channels with functionally and structurally-involved membrane lipids. Virology 432, 485-494 (2012).

4. Schoeman, D. \& Fielding, B. C. Coronavirus envelope protein: current knowledge. Virol. J. 16, 69 (2019).

5. Nieto-Torres, J. L. et al. Severe acute respiratory syndrome coronavirus E protein transports calcium ions and activates the NLRP3 inflammasome. Virology 485, 330-339 (2015)

6. Li, Y., Surya, W., Claudine, S. \& Torres, J. Structure of a conserved Golgi complex-targeting signal in coronavirus envelope proteins. J. Biol. Chem. 289, 12535-12549 (2014)

7. Torres, J. et al. Conductance and amantadine binding of a pore formed by a lysine-flanked transmembrane domain of SARS coronavirus envelope protein. Protein Sci. 16, 2065-2071 (2007).

8. Hong, M. \& DeGrado, W. F. Structural basis for proton conduction and inhibition by the influenza M2 protein. Protein Sci. 21, 1620-1633 (2012).

9. Cady, S. D. et al. Structure of the amantadine binding site of influenza M2 proton channels in lipid bilayers. Nature 463, 689-692 (2010).

10. Pervushin, K. et al. Structure and inhibition of the SARS coronavirus envelope protein ion channel. PLoS Pathog. 5, e1000511 (2009).

11. DeDiego, M. L. et al. A severe acute respiratory syndrome coronavirus that lacks the $\mathrm{E}$ gene is attenuated in vitro and in vivo. J. Virol. 81, 1701-1713 (2007).

12. Nieto-Torres, J. L. et al. Severe acute respiratory syndrome coronavirus envelope protein ion channel activity promotes virus fitness and pathogenesis. PLoS Pathog. 10, e1004077 (2014).

13. Torres, J., Wang, J., Parthasarathy, K. \& Liu, D. X. The transmembrane oligomers of coronavirus protein E. Biophys. J. 88, 1283-1290 (2005).

14. Parthasarathy, K. et al. Expression and purification of coronavirus envelope proteins using a modified $\beta$-barrel construct. Protein Expr. Purif. 85, 133-141 (2012).

15. Arbely, E. et al. A highly unusual palindromic transmembrane helical hairpin formed by SARS coronavirus E protein. J. Mol. Biol. 341, 769-779 (2004).
16. Surya, W., Li, Y. \& Torres, J. Structural model of the SARS coronavirus E channel in LMPG micelles. Biochim. Biophys. Acta 1860, 1309-1317 (2018).

17. Torres, J. et al. Model of a putative pore: the pentameric $\alpha$-helical bundle of SARS coronavirus E protein in lipid bilayers. Biophys. J. 91, 938-947 (2006).

18. Parthasarathy, K. et al. Structural flexibility of the pentameric SARS coronavirus envelope protein ion channel. Biophys. J. 95, L39-L41 (2008).

19. Gullion, T. \& Schaefer, J. Rotational echo double resonance NMR. J. Magn. Reson. 81, 196-200 (1989).

20. Dregni, A. J. et al. In vitro 0 N4R tau fibrils contain a monomorphic $\beta$-sheet core enclosed by dynamically heterogeneous fuzzy coat segments. Proc. Natl Acad. Sci. USA 116, 16357-16366 (2019).

21. Williams, J. K. \& Hong, M. Probing membrane protein structure using water polarization transfer solid-state NMR. J. Magn. Reson. 247, 118-127 (2014).

22. Lesage, A., Emsley, L., Penin, F. \& Bockmann, A. Investigation of dipolar-mediated water-protein interactions in microcrystalline Crh by solid-state NMR spectroscopy. J. Am. Chem. Soc. 128, 8246-8255 (2006).

23. Doherty, T. \& Hong, M. 2D ${ }^{1} \mathrm{H}^{-31} \mathrm{P}$ solid-state NMR studies of the dependence of inter-bilayer water dynamics on lipid headgroup structure and membrane peptides. J. Magn. Reson. 196, 39-47 (2009).

24. Dregni, A. J., Duan, P. \& Hong, M. Hydration and dynamics of full-length tau amyloid fibrils investigated by solid-state nuclear magnetic resonance. Biochemistry 59, 2237-2248 (2020).

25. Mandala, V. S., Loftis, A. R., Shcherbakov, A. A., Pentelute, B. L. \& Hong, M. Atomic structures of closed and open influenza B M2 proton channel reveal the conduction mechanism. Nat. Struct. Mol. Biol. 27, 160-167 (2020).

26. Schwieters, C. D., Kuszewski, J. J., Tjandra, N. \& Clore, G. M. The Xplor-NIH NMR molecular structure determination package. J. Magn. Reson. 160, 65-73 (2003).

27. Choma, C., Gratkowski, H., Lear, J. D. \& DeGrado, W. F. Asparagine-mediated self-association of a model transmembrane helix. Nat. Struct. Biol. 7, 161-166 (2000)

28. Wilson, L., Gage, P. \& Ewart, G. Hexamethylene amiloride blocks E protein ion channels and inhibits coronavirus replication. Virology 353, 294-306 (2006)

29. Chipot, C. et al. Perturbations of native membrane protein structure in alkyl phosphocholine detergents: a critical assessment of NMR and biophysical studies. Chem. Rev. 118, 3559-3607 (2018).

30. Park, S. H. et al. Three-dimensional structure of the channel-forming trans-membrane domain of virus protein "u" (Vpu) from HIV-1. J. Mol. Biol. 333, 409-424 (2003).

31. Lu, J. X., Sharpe, S., Ghirlando, R., Yau, W. M. \& Tycko, R. Oligomerization state and supramolecular structure of the HIV-1 Vpu protein transmembrane segment in phospholipid bilayers. Protein Sci. 19, 1877-96 (2010).

32. Cady, S. D., Goodman, C., Tatko, C. D., DeGrado, W. F. \& Hong, M. Determining the orientation of uniaxially rotating membrane proteins using unoriented samples: a ${ }^{2} \mathrm{H},{ }^{13} \mathrm{C}$, and ${ }^{15} \mathrm{~N}$ solid-state NMR investigation of the dynamics and orientation of a transmembrane helical bundle. J. Am. Chem. Soc. 129, 5719-5729 (2007).

33. Hou, X., Pedi, L., Diver, M. M. \& Long, S. B. Crystal structure of the calcium release-activated calcium channel Orai. Science 338, 1308-1313 (2012).

34. $\mathrm{Xu}, \mathrm{C}$. et al. Computational design of transmembrane pores. Nature $\mathbf{5 8 5}$, 129-134 (2020).

35. Lee, C. et al. The lysosomal potassium channel TMEM175 adopts a novel tetrameric architecture. Nature 547, 472-475 (2017).

36. Kane Dickson, V., Pedi, L. \& Long, S. B. Structure and insights into the function of a Ca ${ }^{2+}$-activated $\mathrm{Cl}^{-}$channel. Nature 516, 213-218 (2014).

37. Yang, T. et al. Structure and selectivity in bestrophin ion channels. Science 346, 355-359 (2014)

38. Nieto-Torres, J. L. et al. Subcellular location and topology of severe acute respiratory syndrome coronavirus envelope protein. Virology 415 69-82 (2011).

39. Duart, G. et al. SARS-CoV-2 envelope protein topology in eukaryotic membranes. Open Biol. 10, 200209 (2020).

40. Abramson, A. et al. An ingestible self-orienting system for oral delivery of macromolecules. Science 363, 611-615 (2019).

Publisher's note Springer Nature remains neutral with regard to jurisdictional claims in published maps and institutional affiliations.

(c) The Author(s), under exclusive licence to Springer Nature America, Inc. 2020 


\section{Methods}

Cloning of recombinant $\operatorname{ETM}(8-38)$. The gene encoding full-length SARS-CoV-2 E protein (NCBI reference sequence YP_009724392.1, residues 1-75) was purchased from Genewiz. The gene encoding the TM domain (residues 8-38, ETGTLIVNSVLLFLAFVVFLLVTLAILTALR) was isolated using PCR and cloned into a Champion pET-SUMO plasmid (Invitrogen). The plasmid was transfected into E. coli BL21 (DE3) cells (Invitrogen) to express the SUMO-ETM fusion protein containing an $\mathrm{N}$-terminal $\mathrm{His}_{6}$ tag (Extended Data Fig. 1a). The construct's DNA sequence was verified by Sanger sequencing (Genewiz).

Expression and purification of $\left[{ }^{13} \mathrm{C},{ }^{15} \mathrm{~N}\right]$ ETM. A glycerol cell swab stored at $-70^{\circ} \mathrm{C}$ was used to start a $10-\mathrm{ml} \mathrm{LB}$ culture containing $50 \mu \mathrm{g} \mathrm{ml}^{-1}$ kanamycin. The starter culture was used to inoculate 21 of LB medium. Cells were grown at $37^{\circ} \mathrm{C}$ until an optical density at $600 \mathrm{~nm}\left(\mathrm{OD}_{600}\right)$ of $0.6-0.8$ was reached, and were collected by centrifugation for $10 \mathrm{~min}$ at $20^{\circ} \mathrm{C}$ and $4,400 \mathrm{~g}$. These $\mathrm{LB}$ cells were resuspended in 11 of $\mathrm{M} 9$ medium ( $\mathrm{pH} 7.8,48 \mathrm{mM} \mathrm{Na}_{2} \mathrm{HPO}_{4}, 22 \mathrm{mM} \mathrm{KH}_{2} \mathrm{PO}_{4}$, $8.6 \mathrm{mM} \mathrm{NaCl}, 4 \mathrm{mM} \mathrm{MgSO}_{4}, 0.2 \mathrm{mM} \mathrm{CaCl}_{2}, 50 \mathrm{mg}$ kanamycin) containing $1 \mathrm{~g} / \mathrm{L}$ ${ }^{15} \mathrm{~N}-\mathrm{NH}_{4} \mathrm{Cl}$. The cells were incubated in $\mathrm{M} 9$ media for $30 \mathrm{~min}$ at $18^{\circ} \mathrm{C}$, then $1 \mathrm{~g} \mathrm{l}^{-1}$ $\left[\mathrm{U}_{-}{ }^{13} \mathrm{C}\right.$ ] glucose dissolved in $5 \mathrm{ml}$ sterile $\mathrm{H}_{2} \mathrm{O}$ and $3 \mathrm{ml} 100 \times$ MEM vitamins were added. The cells were grown for another $30 \mathrm{~min}$, then protein expression was induced by addition of $0.4 \mathrm{mM}$ IPTG along with $2 \mathrm{~g} \mathrm{l}^{-1}\left[\mathrm{U}-{ }^{13} \mathrm{C}\right]$ glucose in $10 \mathrm{ml}$ sterile $\mathrm{H}_{2} \mathrm{O}$. Additional IPTG was added after $1 \mathrm{~h}$ to bring the final concentration to $0.8 \mathrm{mM}$. Protein expression proceeded overnight for $16 \mathrm{~h}$ at $18^{\circ} \mathrm{C}$, reaching an $\mathrm{OD}_{600}$ of 2.5 .

The cells were spun down at $4{ }^{\circ} \mathrm{C}$, and 5,000 r.p.m. for $10 \mathrm{~min}$ and resuspended in $35 \mathrm{ml}$ Lysis Buffer I ( $\mathrm{pH} 8.0,50 \mathrm{mM}$ Tris- $\mathrm{HCl}, 100 \mathrm{mM} \mathrm{NaCl}, 1.0 \%$ Triton X-100, $0.5 \mathrm{mg} \mathrm{ml}^{-1}$ lysozyme, $10 \mu \mathrm{l}$ benozonase nuclease, $1 \mathrm{mM} \mathrm{Mg}^{2+}, 10 \mathrm{mM}$ imidazole). Cells were lysed at $4{ }^{\circ} \mathrm{C}$ by sonication ( $5 \mathrm{~s}$ on and $5 \mathrm{~s}$ off) for $1 \mathrm{~h}$ using a probe sonicator. The soluble fraction of the cell lysate was separated from the inclusion bodies by centrifugation at $17,000 \mathrm{~g}$ for $20 \mathrm{~min}$ at $4{ }^{\circ} \mathrm{C}$. The supernatant was loaded onto a gravity-flow chromatography column containing $\sim 6 \mathrm{ml}$ nickel affinity resin (Profinity IMAC, BioRad) that was pre-equilibrated with Lysis Buffer I. The fractions were bound to the resin for $1 \mathrm{~h}$ by gentle rocking at $4^{\circ} \mathrm{C}$. The column was washed with $50 \mathrm{ml}$ of Wash Buffer I ( $\mathrm{pH} 8.0,50 \mathrm{mM}$ Tris- $\mathrm{HCl}, 100 \mathrm{mM} \mathrm{NaCl}$, $0.1 \%$ DDM, $30 \mathrm{mM}$ imidazole). SUMO-ETM was eluted with $10-15 \mathrm{ml}$ elution buffer ( $\mathrm{pH}$ 8.0, $50 \mathrm{mM}$ Tris- $\mathrm{HCl}, 100 \mathrm{mM} \mathrm{NaCl}, 0.1 \%$ DDM, $250 \mathrm{mM}$ imidazole) (Extended Data Fig. 1b). The eluted protein was diluted to one-third of the original concentration by adding twice the elution volume of dilution buffer $(\mathrm{pH} 8.0,50 \mathrm{mM}$ Tris- $\mathrm{HCl}, 100 \mathrm{mM} \mathrm{NaCl}, 0.1 \% \mathrm{DDM}$ ) to reduce the imidazole concentration before protease cleavage. Approximately $20 \%$ of the protein was found in the insoluble membrane and inclusion body fraction. To purify this fraction, the pelleted mass was resuspended in lysis buffer II (lysis buffer I with added $6 \mathrm{M}$ urea) and rocked gently at $4^{\circ} \mathrm{C}$ overnight. Soluble protein was isolated by centrifugation at $17,000 \mathrm{~g}$ for $20 \mathrm{~min}$ at $4^{\circ} \mathrm{C}$. Nickel affinity column chromatography proceeded as described above for the soluble fraction, except that wash buffer II (wash buffer I with added $3 \mathrm{M}$ urea) was used in place of wash buffer I.

The purified SUMO-ETM from both the soluble and inclusion body fractions was cleaved by adding 1:10 (wt/wt) SUMO protease:SUMO-ETM and $5 \mathrm{mM}$ TCEP for $2 \mathrm{~h}$ at room temperature with gentle rocking. The cleavage efficiency was assessed by analytical HPLC to be $\sim 75 \%$. ETM was purified using preparative RP-HPLC on a Varian ProStar 210 System using an Agilent C3 column $(5-\mu \mathrm{m}$ particle size, $21.2 \mathrm{~mm} \times 150 \mathrm{~mm})$. The protein was eluted using a linear gradient of 5-99\% (9:1, acetonitrile:isopropanol):water containing $0.1 \%$ trifluoroacetic acid

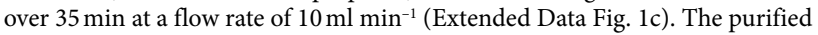
protein was dried down to a film with a stream of nitrogen gas and placed under vacuum overnight. The protein film was stored at $-20^{\circ} \mathrm{C}$. The yield of the purified protein was $10 \mathrm{mg} \mathrm{l}^{-1}$ of M9 medium. Labeling efficiency was $\sim 94 \%$, as estimated by MALDI mass spectrometry (Extended Data Fig. 1d). [U- $\left.{ }^{13} \mathrm{C}\right] \mathrm{ETM}$ and $\left[\mathrm{U}-{ }^{15} \mathrm{~N}\right]$ ETM were expressed and purified using the same protocol but substituting $\left[{ }^{15} \mathrm{~N}\right]$ $\mathrm{NH}_{4} \mathrm{Cl}$ or $\left[{ }^{13} \mathrm{C}\right]$ glucose with unlabeled reagents.

Expression of 4- ${ }^{19}$ F-Phe fluorinated ETM. A glycerol cell swab was used to start a $10 \mathrm{ml} \mathrm{LB}$ culture containing $50 \mu \mathrm{g} \mathrm{ml}^{-1}$ kanamycin. The starter culture was then used to inoculate $2 \mathrm{l}$ of $\mathrm{M} 9$ medium ( $\mathrm{pH} 7.8,48 \mathrm{mM} \mathrm{Na}_{2} \mathrm{HPO}_{4}, 22 \mathrm{mM} \mathrm{KH}_{2} \mathrm{PO}_{4}$, $8.6 \mathrm{mM} \mathrm{NaCl}_{4} 4 \mathrm{mM} \mathrm{MgSO}_{4}, 0.2 \mathrm{mM} \mathrm{CaCl}_{2}, 50 \mathrm{mg}$ kanamycin) containing $3 \mathrm{~g} \mathrm{l}^{-1}$ unlabeled glucose and $1 \mathrm{~g} \mathrm{l}^{-1}$ unlabeled $\mathrm{NH}_{4} \mathrm{Cl}$. The cells were grown in $\mathrm{M} 9$ at $37^{\circ} \mathrm{C}$ for medium for $8 \mathrm{~h}$ until an $\mathrm{OD}_{600}$ of 0.5 was reached. The cells were collected by centrifugation at $4,400 \mathrm{~g}$ for $10 \mathrm{~min}$ at $20^{\circ} \mathrm{C}$, then concentrated into a fresh 1-1 M9 culture and incubated at $30^{\circ} \mathrm{C}$ for $60 \mathrm{~min}$. Subsequently, $1.5 \mathrm{~g} \mathrm{l}^{-1}$ glyphosate was added to halt the pentose phosphate pathway ${ }^{41}$, followed by addition of $115 \mathrm{mg} \mathrm{L}$-Trp, $115 \mathrm{mg} \mathrm{L}$-Tyr and $400 \mathrm{mg}$ of $4{ }^{-1}{ }^{19} \mathrm{~F}-\mathrm{L}-\mathrm{Ph}$ to the culture. After $30 \mathrm{~min}$, IPTG was added to a final concentration of $0.4 \mathrm{mM}$, and protein expression proceeded at $30^{\circ} \mathrm{C}$ for $5.5 \mathrm{~h}$. The cells were collected by centrifugation at $4,400 \mathrm{~g}$ for $10 \mathrm{~min}$ at $4^{\circ} \mathrm{C}$. The pellet was stored at $-70^{\circ} \mathrm{C}$ until purification. Cell lysis and protein purification followed the same protocol, except that the ETM peak during preparative HPLC was collected in 2 fractions of $\sim 1$ min each. Fluorine incorporation in the two fractions was measured using MALDI mass spectrometry. The first fraction had a higher incorporation level of $83 \%$ for all 3 Phe residues labeled with ${ }^{19} \mathrm{~F}$, indicating a per-residue labeling efficiency of $94 \%$ (Extended
Data Fig. 1e). Only this fraction was used to prepare the mixed ${ }^{13} \mathrm{C}$ - and ${ }^{19} \mathrm{~F}$-labeled protein for distance measurement. The final yield of the Phe fluorinated ETM expression was $1.5 \mathrm{mg} \mathrm{l}^{-1}$ of $\mathrm{M} 9$ medium. When the protocol was originally tested using $100 \mathrm{mg} \mathrm{l}^{-1} 4{ }^{19} \mathrm{~F}$-Phe, $1.0 \mathrm{~g} \mathrm{l}^{-1}$ glyphosate, $6 \mathrm{~g} \mathrm{l}^{-1}$ unlabeled glucose and with expression at $18^{\circ} \mathrm{C}$ for $5.5 \mathrm{~h}$, a much lower per-residue labeling efficiency of $\sim 35 \%$ was obtained.

Membrane sample preparation. Eight protein samples were prepared for this study. Five membrane samples contained $\left[{ }^{13} \mathrm{C},{ }^{15} \mathrm{~N}\right]$ ETM and one contained $\left[{ }^{13} \mathrm{C}\right]$ ETM. Another sample contained a 1:1 mixture of ${ }^{13} \mathrm{C}$-labeled protein: $:{ }^{15} \mathrm{~N}$-labeled protein. The last sample contained a 1:1 mixture of ${ }^{13} \mathrm{C}$-labeled protein:4-

${ }^{19} \mathrm{~F}$-Phe-labeled protein. Six of the 8 samples were prepared in a $\mathrm{pH} 7.5$ Tris buffer (20 mM Tris- $\mathrm{HCl}, 5 \mathrm{mM} \mathrm{NaCl}, 2 \mathrm{mM}$ EDTA and $\left.0.2 \mathrm{mM} \mathrm{NaN}_{3}\right)$. One sample was prepared in a pH 5 citrate buffer with calcium $\left(20 \mathrm{mM}\right.$ citrate, $5 \mathrm{mM} \mathrm{CaCl}_{2}$ and $0.2 \mathrm{mM} \mathrm{NaN}_{3}$ ), while the final sample was prepared in the same $\mathrm{pH} 5$ citrate buffer without calcium chloride. Further details about membrane sample preparation and $3-{ }^{19} \mathrm{~F}$-amantadine synthesis are given in Supplementary Note 1.

Solid-state NMR experiments. Most solid-state NMR spectra were measured on a Bruker AVANCE NEO $900 \mathrm{MHz}(21.1 \mathrm{~T})$ spectrometer and an Avance II $800 \mathrm{MHz}$ $(18.8 \mathrm{~T})$ spectrometer using $3.2 \mathrm{~mm}$ HCN probes. ${ }^{13} \mathrm{C}-{ }^{19} \mathrm{~F}$ REDOR experiments were conducted on an Avance III HD $600 \mathrm{MHz}(14.1 \mathrm{~T})$ spectrometer using a $1.9 \mathrm{~mm}$ HFX probe. Magic-angle-spinning (MAS) frequencies were $11.8 \mathrm{kHz}$ for $900-\mathrm{MHz}$ experiments and $14 \mathrm{kHz}$ for the 800 - and $600-\mathrm{MHz}$ experiments. Radiofrequency (RF) field strengths on the $3.2-\mathrm{mm}$ probes were $50-91 \mathrm{kHz}$ for ${ }^{1} \mathrm{H}, 50-63 \mathrm{kHz}$ for ${ }^{13} \mathrm{C}$ and $33-42 \mathrm{kHz}$ for ${ }^{15} \mathrm{~N}$. RF field strengths on the $1.9-\mathrm{mm}$ MAS probe were $83-130 \mathrm{kHz}$ for ${ }^{1} \mathrm{H}, 62.5 \mathrm{kHz}$ for ${ }^{13} \mathrm{C}$ and $71 \mathrm{kHz}$ for ${ }^{19} \mathrm{~F}$. Sample temperatures are direct readings from the probe thermocouple, whereas actual sample temperatures are $5-15 \mathrm{~K}$ higher at the MAS frequencies employed. ${ }^{13} \mathrm{C}$ chemical shifts are reported on the tetramethylsilane scale using the adamantane $\mathrm{CH}_{2}$ chemical shift at $38.48 \mathrm{ppm}$ as an external standard. ${ }^{15} \mathrm{~N}$ chemical shifts are reported on the liquid ammonia scale using the $\mathrm{N}$-acetylvaline peak at $122.00 \mathrm{ppm}$ as an external standard.

$2 \mathrm{D}{ }^{13} \mathrm{C}-{ }^{13} \mathrm{C}$ correlation experiments were conducted using combined-driven (CORD) mixing ${ }^{42}$ for ${ }^{13} \mathrm{C}$ spin diffusion. $2 \mathrm{D}$ and $3 \mathrm{D}{ }^{15} \mathrm{~N}-{ }^{13} \mathrm{C}$ correlation spectra, namely, NCACX, NCOCX and CONCA ${ }^{43}$, were measured on the $900-\mathrm{MHz}$ spectrometer. These experiments used spectrally induced filtering in combination with cross-polarization (SPECIFIC-CP) ${ }^{44}$ for heteronuclear polarization transfer. Water-edited $2 \mathrm{D}^{15} \mathrm{~N}-{ }^{13} \mathrm{C} \alpha$ correlation spectra were measured under $11.8-\mathrm{kHz}$ MAS ${ }^{20,21}$ using ${ }^{1} \mathrm{H}$ mixing times of $9 \mathrm{~ms}$ and $100 \mathrm{~ms}$. $2 \mathrm{D}^{15} \mathrm{~N}-{ }^{13} \mathrm{C}$ correlation spectra were measured using an out-and-back transferred-echo double resonance (TEDOR) pulse sequence on the $800 \mathrm{MHz} \mathrm{NMR}^{45}$. Intermolecular $2 \mathrm{D} \mathrm{NHHC}$ correlation spectra ${ }^{46}$ were measured used $0.5 \mathrm{~ms}$ and $1 \mathrm{~ms}{ }^{1} \mathrm{H}-{ }^{1} \mathrm{H}$ mixing. $1 \mathrm{D}$ and $2 \mathrm{D}{ }^{13} \mathrm{C}-{ }^{19} \mathrm{~F}$ REDOR experiments ${ }^{19,47,48}$ were used to measure distances between $4-{ }^{19} \mathrm{~F}$-Phe-labeled and ${ }^{13} \mathrm{C}$-labeled ETM, and between ${ }^{13} \mathrm{C}$-labeled ETM and $3-{ }^{19} \mathrm{~F}-\mathrm{AMT}$. Detailed parameters for the solid-state NMR experiments are given in Supplementary Table 6. Details for the ${ }^{13} \mathrm{C}-{ }^{19} \mathrm{~F}$ REDOR simulations and fitting are given in Supplementary Notes.

NMR spectral analysis. NMR spectra were processed in the TopSpin software and chemical shifts were assigned in Sparky ${ }^{49}$. TALOS-N ${ }^{50}$ was used to calculate torsion angles $(\phi, \psi)$ after converting the ${ }^{13} \mathrm{C}$ chemical shifts to the DSS scale. Residue-specific chemical shift differences $(\Delta \delta)$ between drug-bound and apo samples were calculated from the measured ${ }^{13} \mathrm{C}$ and ${ }^{15} \mathrm{~N}$ chemical shifts $(\delta)$ according to:

$$
\Delta \delta=\sqrt{\left[\sum_{C_{i}}\left(\delta_{C_{i}}^{\text {drug }}-\delta_{C_{i}}^{\mathrm{apo}}\right)^{2}+\frac{\left(\delta_{N}^{\text {drug }}-\delta_{N}^{\mathrm{apo}}\right)^{2}}{2.5}\right]}
$$

2D heatmaps of normalized water-edited 2D NCA spectra were generated using an in-house Python script that removes spectral noise while calculating intensity ratios. The intensities of the $9 \mathrm{~ms}$ and $100 \mathrm{~ms}$ spin diffusion spectra of the ERGIC-bound ETM were read using the NMRglue package ${ }^{51}$. Spectral intensity was noise-filtered by setting signal lower than 3.5 times the average noise level in an empty region of the $2 \mathrm{D}$ spectrum to zero for the $\mathrm{S}$ spectrum and to a large number for the $S_{0}$ spectrum ${ }^{24,25}$. The intensities were divided and scaled by the number of scans to obtain a $2 \mathrm{D}$ contour map that reflect the peak intensity ratios between the 9-ms and 100-ms spectra.

The water accessibility data for the high-pH influenza BM2 proton channel (Fig. 2f) were originally measured in $2 \mathrm{D}^{13} \mathrm{C}-{ }^{13} \mathrm{C}$ correlation spectra with $4 \mathrm{~ms}$ (S) and $100 \mathrm{~ms}\left(\mathrm{~S}_{0}\right)^{1} \mathrm{H}$ spin diffusion ${ }^{25}$. To allow comparison with the ETM spectra measured at $9 \mathrm{~ms}$ and $100 \mathrm{~ms}$ mixing, we scaled the BM2 S $(4 \mathrm{~ms}) / \mathrm{S}_{0}(100 \mathrm{~ms})$ ratios by the integrated aliphatic intensity ratio of 1.976 between the 1D BM2 water-edited spectra measured with $9 \mathrm{~ms}$ and $4 \mathrm{~ms}$ of mixing. This scaling factor was verified to be accurate for two resolved sites, Thr 24 and Gly 26 , in the $1 \mathrm{D}^{13} \mathrm{C}$ spectra.

XPLOR-NIH structure calculations and analysis. Initial structure calculation using ambiguous interhelical restraints, where each helix can contact both 
neighboring helices, did not converge. Thus, we generated parallel pentameric models to specify the direction of ${ }^{13} \mathrm{C}-{ }^{19} \mathrm{~F}$ and NHHC distance restraints where possible. The models take into account the water- and lipid-edited spectra to qualitatively identify the pore- versus lipid-facing orientations of the residues. The best-case ideal helix model (Extended Data Fig. 7a), with 3.5 residues per helical turn, places Asn 15 at the pore-facing $d$ position and Phe20 at the lipid-facing $b$ position, in agreement with the water-edited spectra. However, the model conflicts substantially with other data. For example, Thr35(c) (Thr35 at position $c$ ) and Leu31 $(f)$ are lipid-facing in this model, which contradict the water-edited spectra; Val29 $(d)$ and Phe26 $(a)$ are pore-facing, which contradict the water- and lipid-edited spectra. The arc of Phe20(b), Phe23(e) and FPhe6(a) on the helical wheel makes it unlikely to establish interhelical Phe-Phe contacts, thus contradicting the ${ }^{13} \mathrm{C}-{ }^{19} \mathrm{~F}$ distance data.

Since the ideal-helix geometry cannot agree with all experimental data, we sought better models by including slight deviations from an ideal helix. We turned to the measured chemical shifts to determine where such a deviation is most likely to occur. The C $\beta$ chemical shift of L21 is $1.4 \mathrm{ppm}$ downfield from the average of all other helical Leu residues (Extended Data Fig. 3b), suggesting that the helix is disordered between Phe20 and Phe23. Indeed, such a disorder was already noted in previous solution NMR data ${ }^{10}$. We generated four alternative pentamer models with varying positions and degrees of helix disorder (Extended Data Fig. 7b-e and Supplementary Table 4). Only one model (model 5), generated by a small rotation angle advance of $\sim 50^{\circ}$ at Phe23, adequately reproduces all key features of the experimental data. This model places Asn15(d) and Val25(d) at the same pore-facing position and the three aromatic residues at the arc of Phe20(c), Phe23(f) and Phe26(b). This model was then used to disambiguate the $\mathrm{NHHC}$ and ${ }^{13} \mathrm{C}-{ }^{19} \mathrm{~F}$ distance restraints (Supplementary Tables 2 and 3) by mainly considering only residues that are fewer than four residues away in the primary sequence and that are in close proximity between two helical wheels. With this approach, 42 of the 87 interhelical restraints were set to be unambiguous. In principle, the handedness of the helical bundle can be determined from the registry of interhelical contacts if the position of interfacial residues are known. However, remaining ${ }^{13} \mathrm{C}$ and ${ }^{15} \mathrm{~N}$ chemical-shift overlap among the many hydrophobic residues precluded unequivocal determination of the handedness of the helical bundle. Orthogonal experimental constraints, such as backbone $\mathrm{N}-\mathrm{H}$ bond orientations, which would directly probe the helix tilt angle, will be needed to obtain a higher-resolution structure.

As has been previously described ${ }^{25}$, the ETM structure was calculated using XPLOR-NIH ${ }^{26}$ hosted on the NMRbox ${ }^{52}$. The calculation contained two stages. In the first stage, five extended ETM monomers were placed in a parallel pentamer geometry with each monomer located $20 \AA$ from the center of the pentamer. A total of 120 independent simulated annealing runs were performed with 5,000 steps of torsion angle dynamics at $5,000 \mathrm{~K}$, followed by annealing to $20 \mathrm{~K}$ in decrements of $20 \mathrm{~K}$ with 100 steps at each temperature. After the annealing, energy minimizations in torsion angle and Cartesian coordinates were carried out. The five monomers were restrained to be identical in the annealing step using the non-crystallographic symmetry term PosDiffPot and the translational symmetry term DistSymmPot. Chemical-shift-derived torsion angles $(\phi, \psi)$ predicted by TALOS-N were implemented with the dihedral-angle restraint term $\mathrm{CDIH}$, with ranges set to the higher value between twice the TALOS-N predicted uncertainty and $20^{\circ}$. Measured interhelical distance restraints were implemented using the NOE potential. Distance upper limits were set to $9.0 \AA$ and $11.5 \AA$ for $500 \mu \mathrm{s}$ and $1,000 \mu \mathrm{s}$ of ${ }^{1} \mathrm{H}-{ }^{1} \mathrm{H}$ mixing for the NHHC constraints. Negative REDOR contacts, that is, ${ }^{13} \mathrm{C}$ sites without dephasing, were implemented as two NOE's: one to each neighboring helix. Implicit hydrogen bonds using the hydrogen-bonding database potential term HBDB were implemented during annealing to favor the formation of the $\alpha$-helical conformation. Finally, standard XPLOR potentials were used to restrain the torsion angles using a structural database with the term TorsionDB, and standard bond angles and lengths were set with terms BOND, ANGL, IMPR and RepelPot. The structures were sorted by energy, using all the potentials in the calculation. The scales for all potentials are given in Supplementary Table 5 .

In the second stage, the three lowest-energy structures from the annealing stage were used as independent inputs for structure refinement. A total of 64 independent XPLOR-NIH runs from each of the three starting structures were performed with 5,000 steps of torsion angle dynamics at $1,000 \mathrm{~K}$ followed by annealing to $20 \mathrm{~K}$ in decrements of $10 \mathrm{~K}$ with 100 steps at each temperature. This was followed by energy minimizations in torsion angle and Cartesian coordinates. All the potentials employed in annealing were also used during refinement, with two additions. The ${ }^{13} \mathrm{C}-{ }^{13} \mathrm{C}$ correlations were implemented as intramolecular NOE restraints with an upper limit of $8.0 \AA$. Inter-residue cross-peaks to long hydrophobic side chains, such as Phe, Ile, and Leu, were sometimes violated. Consequently, the upper limits for these $5 \%$ of restraints were increased to $12.0 \AA$ Explicit hydrogen bonds for residues Ile13 (hydrogen-bonded to Val17)-Asn15 (hydrogen-bonded to Leu19) and Phe23 (hydrogen-bonded to Leu27)-Thr30 (hydrogen-bonded to Leu34) were substituted for implicit hydrogen bonds using the same HBDB potential. Finally, the scales of the NOE, Repel and TorsionDB potentials were increased (Supplementary Table 5). All 192 structures from the three independent runs were pooled and sorted using the CDIH, NOE, HBDB
BOND, ANGL, IMPR, Repel and Repel14 potentials, while excluding PosDiffPot, DistSymmPot and TorsionDB potentials. The ten structures with the lowest energies across the specified potentials were included in the final structural ensemble. Where single-structure images are shown, the most representative conformer, selected as the model with the lowest average r.m.s.d. for residues 10-36 with respect to all the other structural models, is shown. The Ramachandran plot statistics for the final structure ensemble are as follows: $93 \%$ of residues are in favored regions, $5 \%$ of residues are in allowed regions and $2 \%$ of residues are in disallowed regions. The only outlier is Leu37, which is outside the TM helix, near the $\mathrm{C}$ terminus.

Graphical images depicting the structures were generated in PyMOL v2.3.4. The reported channel radii were calculated using the HOLE program ${ }^{53}$, and represent the radii of the largest sphere that can be accommodated from exclusion of the van der Waals diameter of all atoms at each $X Y$ plane along the $Z$ channel coordinate, which is collinear with the bilayer normal and the putative direction of ion permeation. The cutoff radius for the calculation was $5 \AA$. The HOLE output was visualized in PyMOL by setting the van der Waals radius of the HOLE-generated spheres 'SPH' to the B-factor values of the SPH output. Details of HMA docking to ETM are given in Supplementary Notes.

Reporting Summary. Further information on research design is available in the Nature Research Reporting Summary linked to this article.

\section{Data availability}

NMR chemical shifts, distance and torsion-angle restraints have been deposited in the Biological Magnetic Resonance Bank (BMRB) with ID numbers 30795. The structural coordinates for ETM have been deposited in the Protein Data Bank with the accession code $7 \mathrm{~K} 3 \mathrm{G}$.

\section{Code availability}

NMR pulse programs and in-house Python scripts used for structure calculation and data analysis such as water-edited spectral analysis are available upon request.

\section{References}

41. Lehninger, A. L., Nelson, D. L. \& Cox, M. M. Principles of Biochemistry (Worth Publishers, 1993).

42. Hou, G., Yan, S., Trebosc, J., Amoureux, J. P. \& Polenova, T. Broadband homonuclear correlation spectroscopy driven by combined $\mathrm{R} 2{ }_{n}{ }^{v}$ sequences under fast magic angle spinning for NMR structural analysis of organic and biological solids. J. Magn. Reson. 232, 18-30 (2013).

43. Rienstra, C. M., Hohwy, M., Hong, M. \& Griffin, R. G. $2 \mathrm{D}$ and $3 \mathrm{D}{ }^{15} \mathrm{~N}^{-13} \mathrm{C}-{ }^{13} \mathrm{C}$ NMR chemical shift correlation spectroscopy of solids: assignment of MAS spectra of peptides. J. Am. Chem. Soc. 122, 10979-10990 (2000).

44. Baldus, M., Petkova, A. T., Herzfeld, J. \& Griffin, R. G. Cross polarization in the tilted frame: assignment and spectral simplification in heteronuclear spin systems. Mol. Phys. 95, 1197-1207 (1998).

45. Hong, M. \& Griffin, R. G. Resonance assignment for solid peptides by dipolar-mediated ${ }^{13} \mathrm{C} /{ }^{15} \mathrm{~N}$ correlation solid-state NMR. J. Am. Chem. Soc. 120 7113-7114 (1998).

46. Lange, A., Luca, S. \& Baldus, M. Structural constraints from proton-mediated rare-spin correlation spectroscopy in rotating solids. J. Am. Chem. Soc. 124, 9704-9705 (2002).

47. Shcherbakov, A. A. \& Hong, M. Rapid measurement of long-range distances in proteins by multidimensional ${ }^{13} \mathrm{C}-{ }^{19} \mathrm{~F}$ REDOR NMR under fast magic-angle spinning. J. Biomol. NMR 71, 31-43 (2018).

48. Shcherbakov, A. A., Roos, M., Kwon, B. \& Hong, M. Two-dimensional ${ }^{19} \mathrm{~F}^{13} \mathrm{C}$ correlation NMR for ${ }^{19} \mathrm{~F}$ resonance assignment of fluorinated proteins. J. Biomol. NMR 74, 193-204 (2020).

49. Lee, W., Tonelli, M. \& Markley, J. L. NMRFAM-SPARKY: enhanced software for biomolecular NMR spectroscopy. Bioinformatics 31, 1325-1327 (2014)

50. Shen, Y. \& Bax, A. Protein backbone and sidechain torsion angles predicted from NMR chemical shifts using artificial neural networks. J. Biomol. NMR 56, 227-241 (2013).

51. Helmus, J. J. \& Jaroniec, C. P. Nmrglue: an open source Python package for the analysis of multidimensional NMR data. J. Biomol. NMR 55, 355-367 (2013).

52. Maciejewski, M. W. et al. NMRbox: a resource for biomolecular NMR computation. Biophys. J. 112, 1529-1534 (2017).

53. Smart, O. S., Neduvelil, J. G., Wang, X., Wallace, B. A. \& Sansom, M. S. HOLE: a program for the analysis of the pore dimensions of ion channel structural models. J. Mol. Graph 14, 354-360 (1996).

\section{Acknowledgements}

This research is funded by National Institutes of Health grant GM088204 to M.H and the MIT School of Science Sloan Fund to V.S.M. and A.A.S. The experiments made use of NMR spectrometers at the MIT/Harvard Center for Magnetic Resonance, supported 
by NIH grant P41 GM132079. Structure calculation made use of NMRbox, supported by NIH grant P41 GM111135.

\section{Author contributions}

M.H. designed the project and supervised experiments and data analysis. V.S.M., M.J.M. and A.A.S. cloned, expressed and purified the protein and conducted the solid-state NMR experiments. V.S.M. and M.J.M. assigned and analyzed the spectra. V.S.M. calculated the structure with contributions from A.J.D. and M.J.M. A.A.S. conducted ${ }^{19} \mathrm{~F}$ NMR experiments, simulations and docking. A.K. synthesized fluorinated amantadine. All authors discussed the results of the study and wrote the paper.

\section{Competing interests}

The authors declare no competing interests.

\section{Additional information}

Extended data is available for this paper at https://doi.org/10.1038/s41594-020-00536-8. Supplementary information is available for this paper at https://doi.org/10.1038/ s41594-020-00536-8.

Correspondence and requests for materials should be addressed to M.H.

Peer review information Peer reviewer reports are available. Florian Ullrich and Inês Chen were the primary editors on this article and managed its editorial process and peer review in collaboration with the rest of the editorial team. Nature Structural and Molecular Biology thanks Tatyana Polenova and Jaume Torres for their contribution to the peer review of this work.

Reprints and permissions information is available at www.nature.com/reprints. 
a His-tag

SUMO-tag

HHHHHHGSGL VPRGSASMSD SEVNQEAKPE VKPEVKPETH INLKVSDGSS EIFFKIKKTT PLRRLMEAFA KRQGKEMDSL RFLYDGIRIQ ADQTPEDLDM EDNDIIEAHR EQIGG ETGTLIVNSV LLFLAFVVFL LVTLAILTAL $R$ SARS-COV-2 E(8-38)

b Soluble Fraction Membrane/IB Fraction

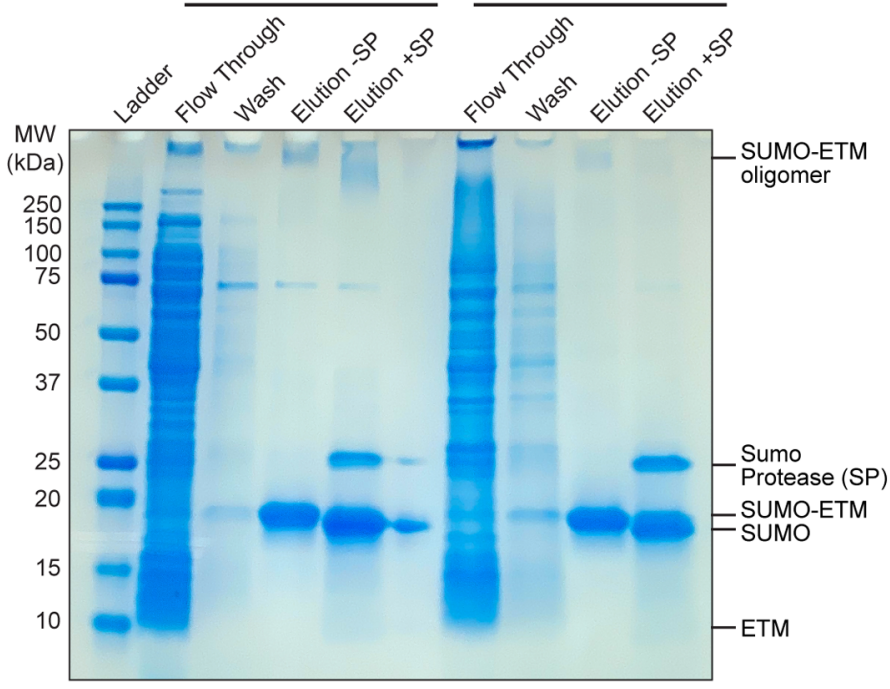

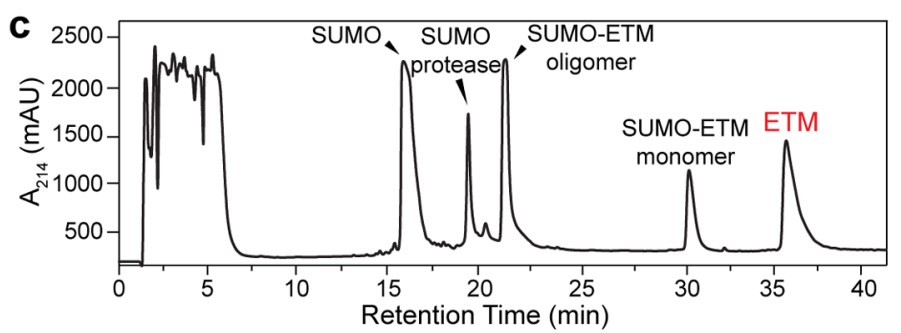

d $U-{ }^{13} \mathrm{C},{ }^{15} \mathrm{~N}-\mathrm{ETM}$

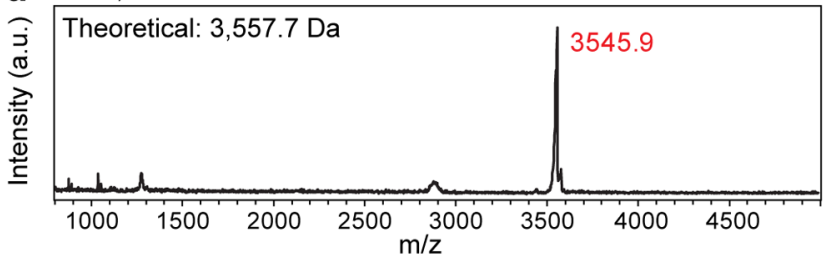

e ${ }^{19}$ F-ETM

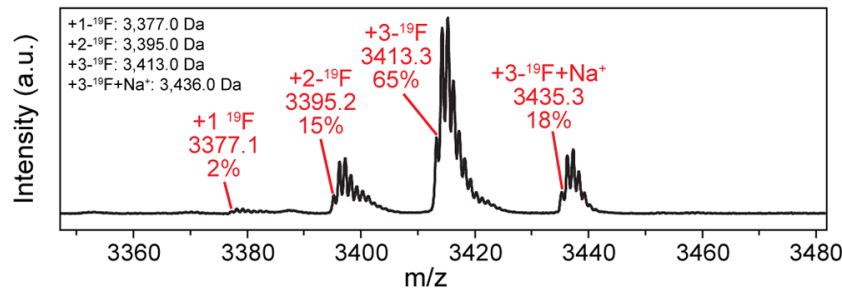

Extended Data Fig. 1 | Cloning, purification and characterization of ETM. a, Amino acid sequence of SUMO-tagged ETM. b, SDS-PAGE gel showing purification of ETM by nickel affinity column chromatography. The flowthrough contains all soluble proteins that have low affinity for nickel. The column was washed with $30 \mathrm{mM}$ imidazole, and SUMO-ETM (18 kDa band) was eluted at $>90 \%$ purity with $250 \mathrm{mM}$ imidazole. High molecular-weight SUMO-ETM oligomers are visible as a minor species. ETM was cleaved from the SUMO tag using SUMO protease. c, Preparative reverse-phase HPLC chromatogram after protease cleavage. ETM elutes at $37.5 \mathrm{~min}$. d, MALDI mass spectrum of purified $\mathrm{U}-{ }^{13} \mathrm{C},{ }^{15} \mathrm{~N}$ labeled ETM. e, MALDI mass spectrum of purified $4{ }^{19} \mathrm{~F}$-Phe labeled ETM. The measured masses are in good agreement with the theoretical masses. $83 \%$ of the $4-{ }^{19} \mathrm{~F}$-Phe labeled ETM monomers have all three Phe residues fluorinated, indicating a per-site labeling efficiency of $94 \%$. 

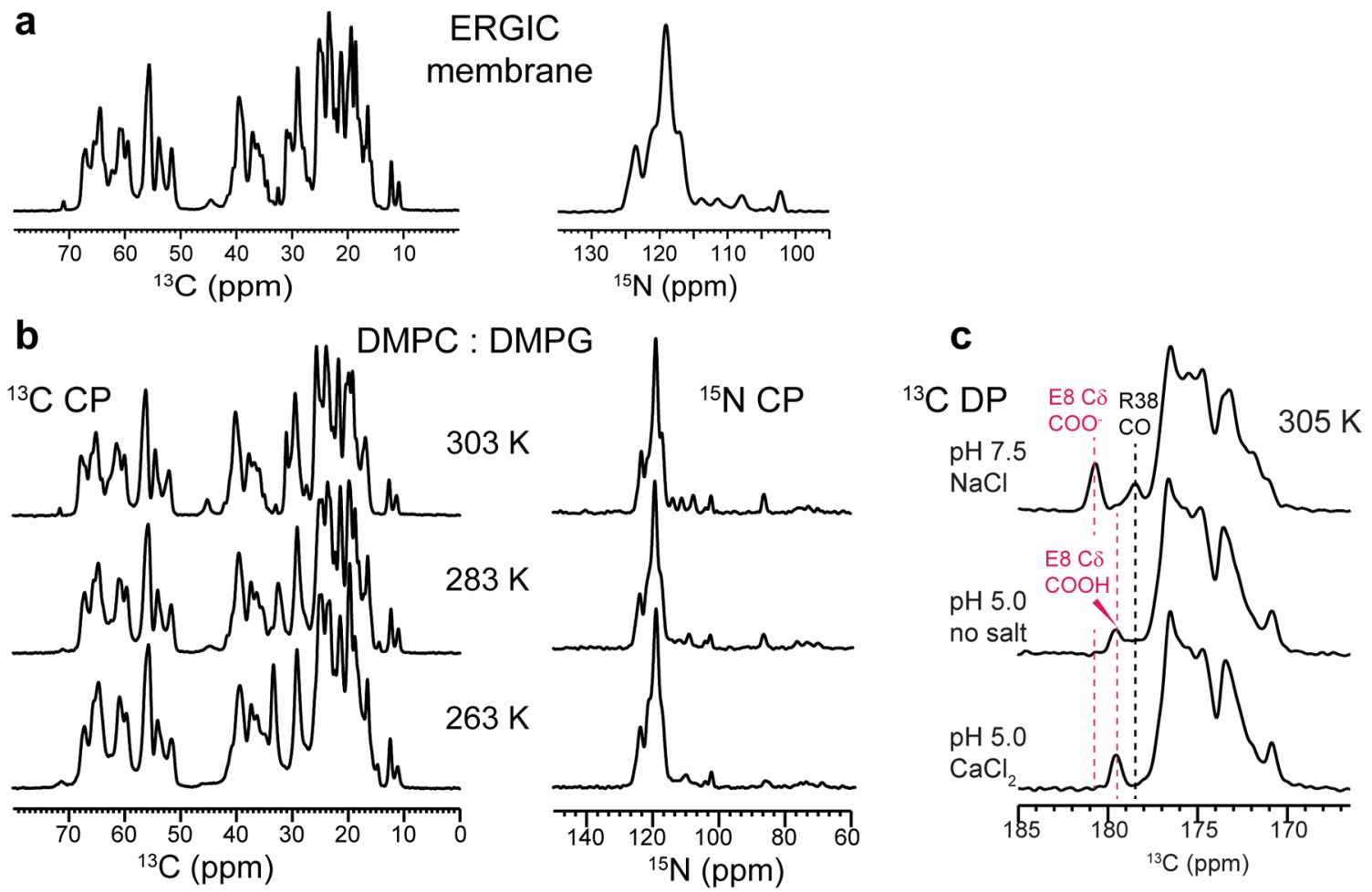

d NCA ERGIC, $293 \mathrm{~K}$; DMPX, $303 \mathrm{~K}$
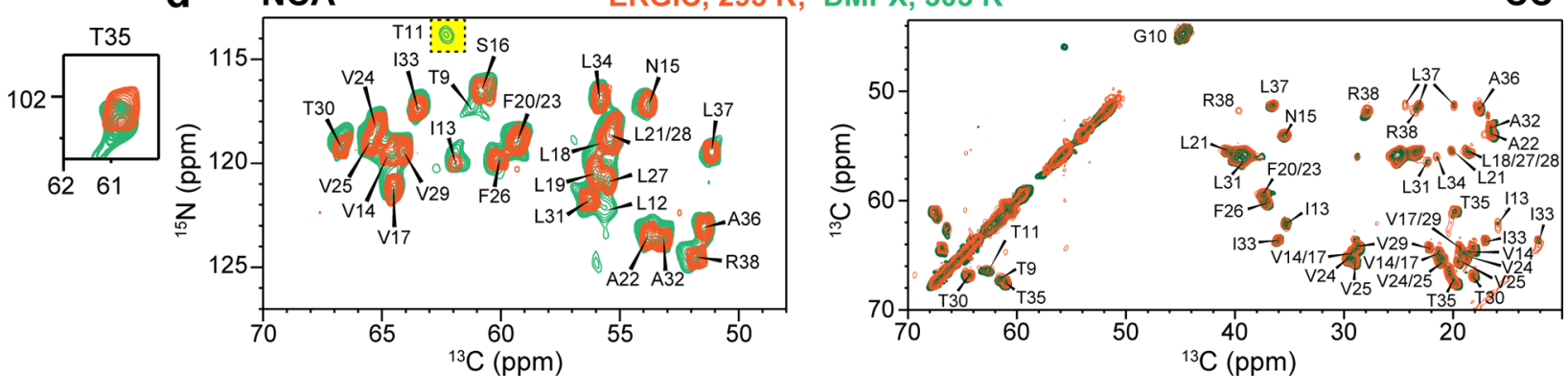

e
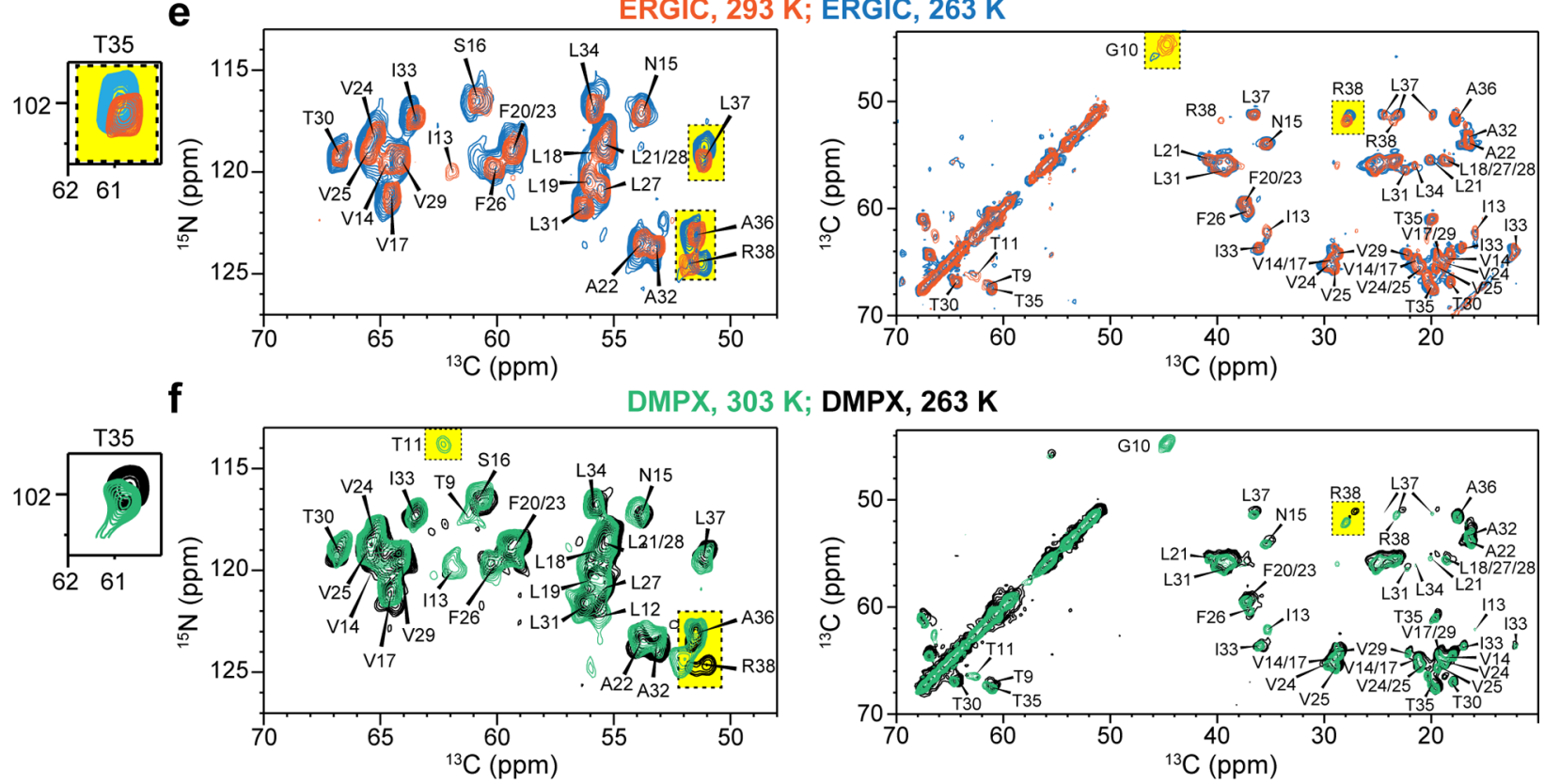

Extended Data Fig. 2 | See next page for caption. 
Extended Data Fig. 2 | Effects of temperature and membrane composition on ETM structure. a, ${ }^{13} \mathrm{C}$ and ${ }^{15} \mathrm{~N}$ CP-MAS spectra of ERGIC-bound ETM. The spectra show high sensitivity and resolution, indicating a well ordered and rigid protein. $\mathbf{b},{ }^{13} \mathrm{C}$ and ${ }^{15} \mathrm{~N} \mathrm{CP}-\mathrm{MAS}$ spectra of ETM in DMPX membranes from $303 \mathrm{~K}$ to $263 \mathrm{~K}$. The spectral intensities and linewidths are insensitive to temperature, indicating that the protein is mostly immobilized at ambient temperature. $\mathbf{c}^{13} \mathrm{C}$ direct-polarization (DP) spectra of DMPX-bound ETM. The E8 sidechain carboxyl chemical shift changes between high and low pH, indicating that this residue is protonated at low pH. d-f, $2 \mathrm{D}{ }^{15} \mathrm{~N}-{ }^{13} \mathrm{C}$ (left) and ${ }^{13} \mathrm{C}-{ }^{-13} \mathrm{C}$ (right) correlation spectra of ETM at high and low temperatures and in ERGIC versus DMPX membranes. Yellow rectangles highlight peaks with clear chemical shift or intensity changes. d, 2D spectra of ERGIC-bound ETM (orange) at $293 \mathrm{~K}$ and DMPX-bound ETM at $303 \mathrm{~K}$ (green). The chemical shifts are similar, indicating that the protein conformation is unaffected by the presence of POPS, POPI and cholesterol. T11 and L12 signals are not detected in the ERGIC sample at this temperature, suggesting that the N-terminus is mobile under these conditions. e, 2D spectra of ERGIC-bound ETM at 293 K (orange) and 263K (blue). Moderate chemical shift changes are observed for C-terminal residues from T35 to R38, while the 113 signal is not visible at low temperature. f, 2D spectra of DMPX-bound ETM at $303 \mathrm{~K}$ ( $g$ reen) and $263 \mathrm{~K}$ (purple). The C-terminal residues exhibit temperature-dependent chemical shifts, similar to the ERGIC-bound peptide. The N-terminal residues of T9 to 113 do not exhibit signals at $263 \mathrm{~K}$, indicating that the $\mathrm{N}$-terminus undergoes intermediate-timescale motion at this temperature. Thus, the $\mathrm{C}$-terminal conformation is temperature-dependent while the $\mathrm{N}$-terminus is dynamic at high temperature. 
a

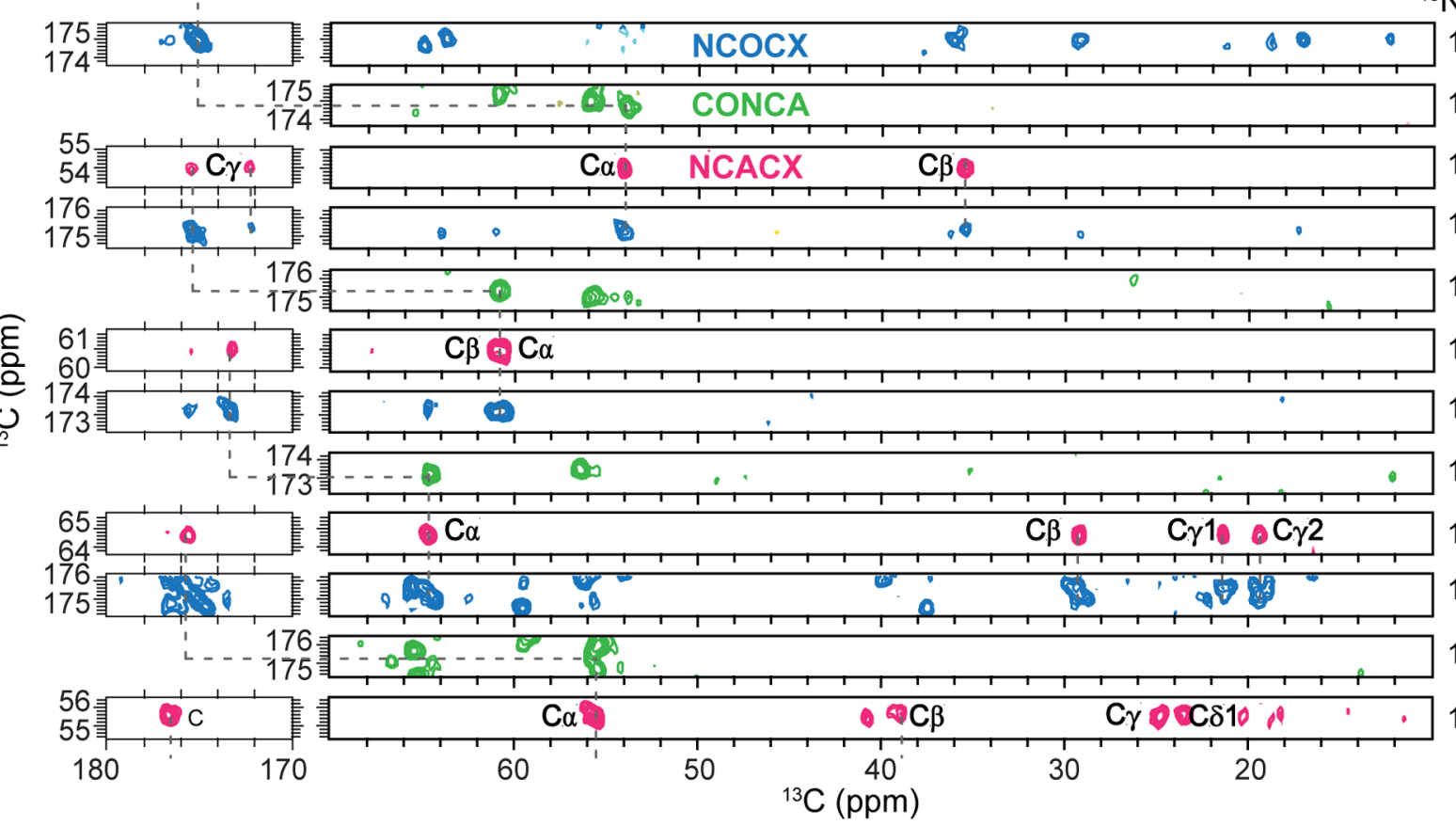

${ }^{15} \mathrm{~N}(\mathrm{ppm})$

117.0

$$
\text { rinting }
$$
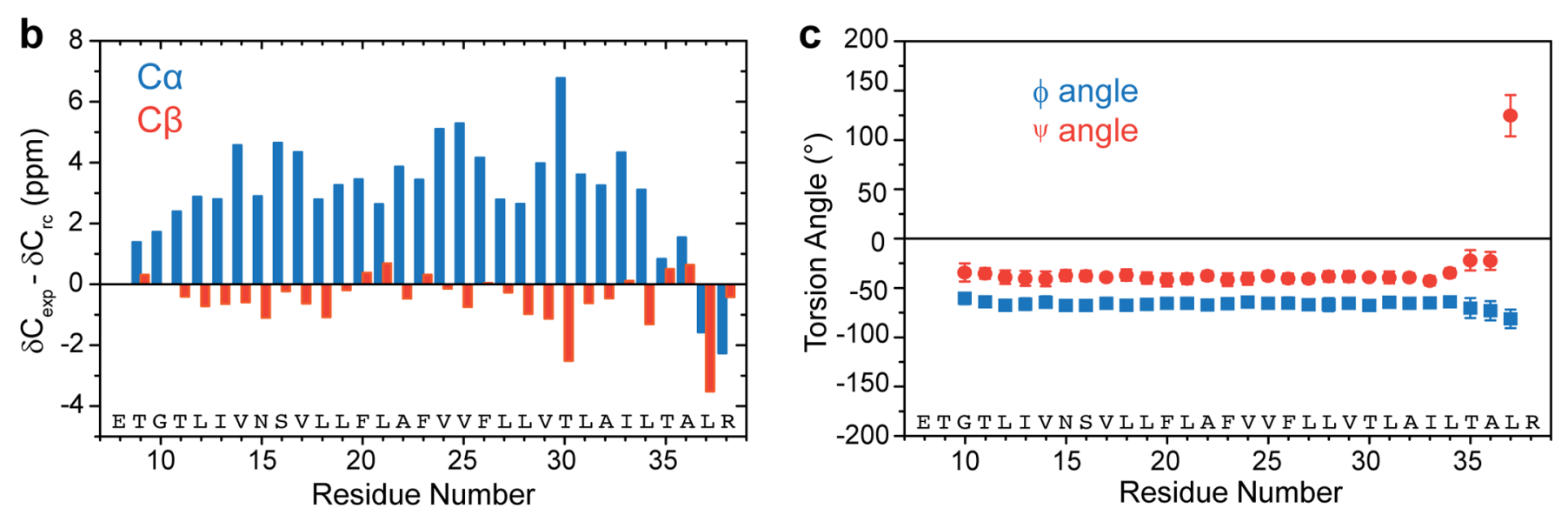

Extended Data Fig. 3 | Chemical shift assignment and secondary structure of ETM. a, Representative strips from 3D NCACX (magenta), CONCA (green) and NCOCX (blue) spectra of ERGIC-membrane bound ETM. These spectra allow full assignment of the ${ }^{13} \mathrm{C}$ and ${ }^{15} \mathrm{~N}$ chemical shifts. $\mathbf{b}, \mathrm{C} \alpha$ (blue) and $\mathrm{C} \beta$ (orange) secondary chemical shifts compared to random coil chemical shifts. Most residues show positive $C \alpha$ and negative $C \beta$ secondary shifts, indicating an $\alpha$-helical conformation. c, ( $\varphi, \psi)$ torsion angles calculated using TALOS-N. Residues G10 to L34 show $\alpha$-helical conformation. Error bars represent the precision of the TALOS-N prediction, defined as one standard deviation for the $(\varphi, \psi)$ angles among the best-matched peptides for each residue. 

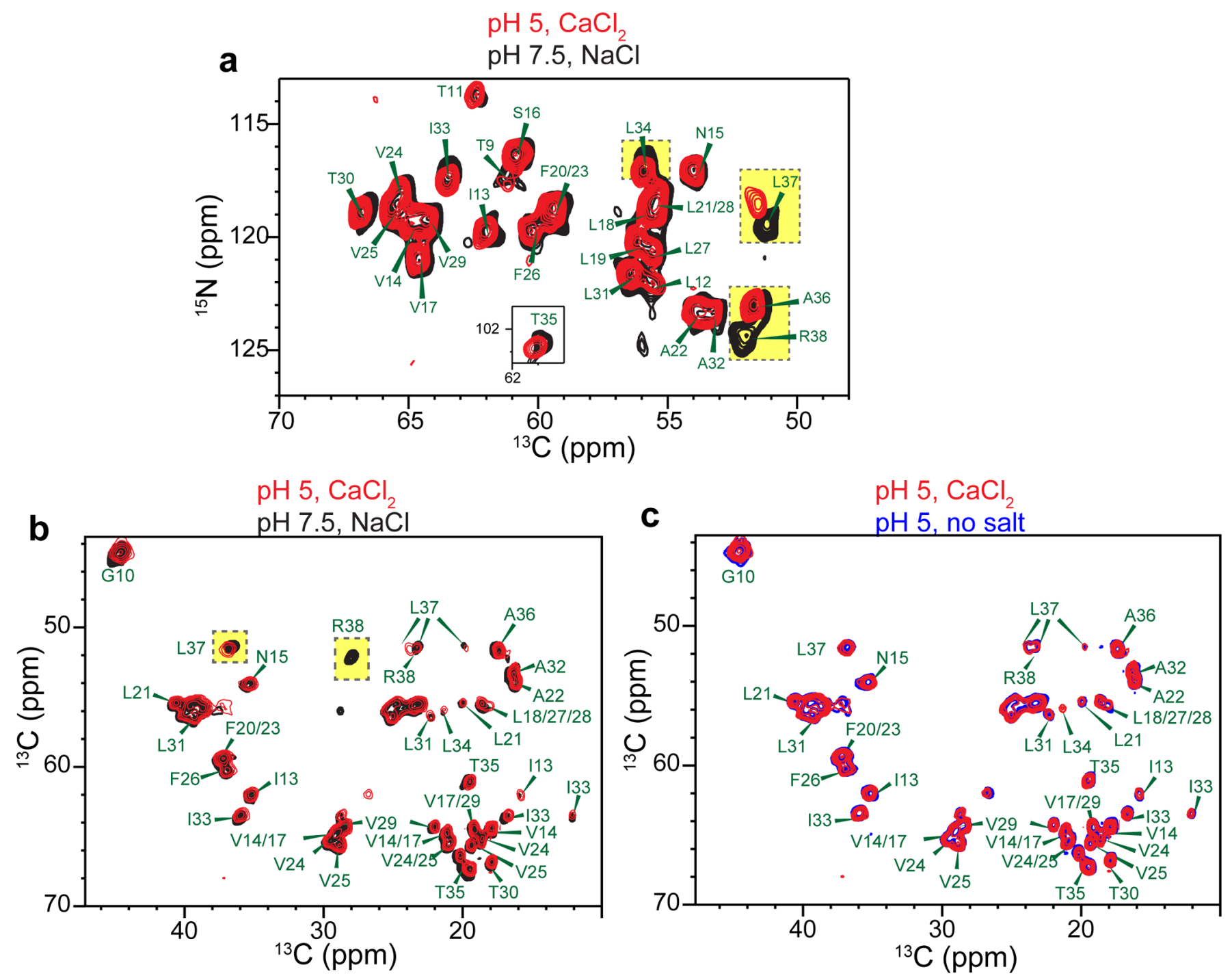

Extended Data Fig. 4 | Effects of pH and ions on the chemical shifts of DMPX-membrane bound ETM. Where cations are present, the ion concentration is $5 \mathrm{mM}$. a, $2 \mathrm{D}^{15} \mathrm{~N}-{ }^{-13} \mathrm{C} \alpha$ correlation spectra of high-pH ETM with $5 \mathrm{mM} \mathrm{NaCl}$ and low-pH ETM with $5 \mathrm{mM} \mathrm{CaCl}_{2}$. Chemical shift changes are observed for C-terminal residues such as R38, L37 and L34 (yellow highlight). b, $2 \mathrm{D}{ }^{13} \mathrm{C}-{ }^{13} \mathrm{C}$ correlation spectra of low-pH ETM with $\mathrm{CaCl}$ and high-pH ETM with NaCl. c, $2 \mathrm{D}^{13} \mathrm{C}-{ }^{-13} \mathrm{C}$ correlation spectrum of low-pH ETM with $\mathrm{CaCl}_{2}$ and low-pH ETM without salt. These spectra indicate that the chemical shift changes mainly result from $\mathrm{pH}$ changes. 
a $4 \mathrm{~F}-\mathrm{Phe}: \mathrm{CN}$ labeled $\operatorname{ETM}(1: 1)$

CN-labeled ETM
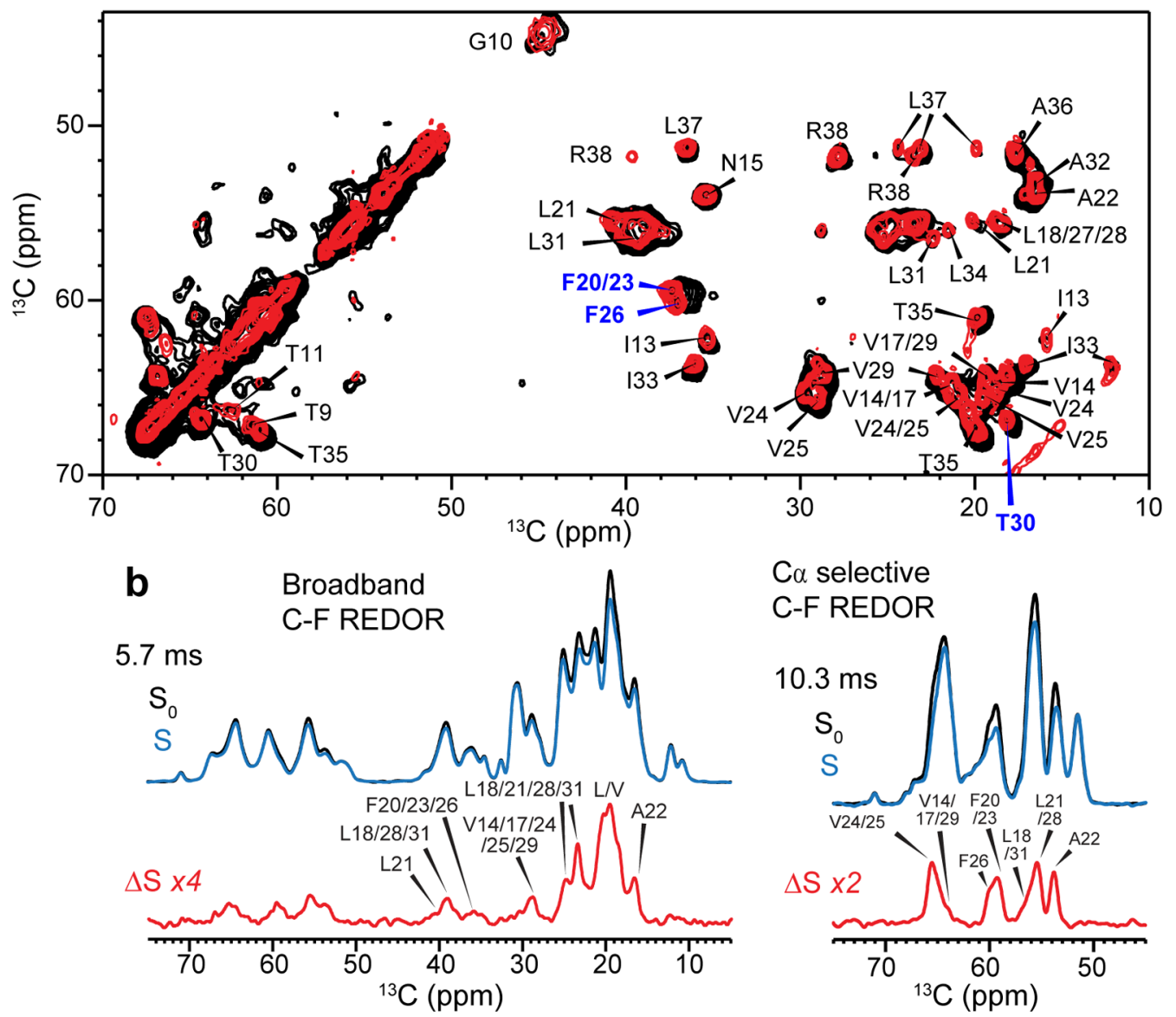

C Broadband REDOR

Ca-selective REDOR
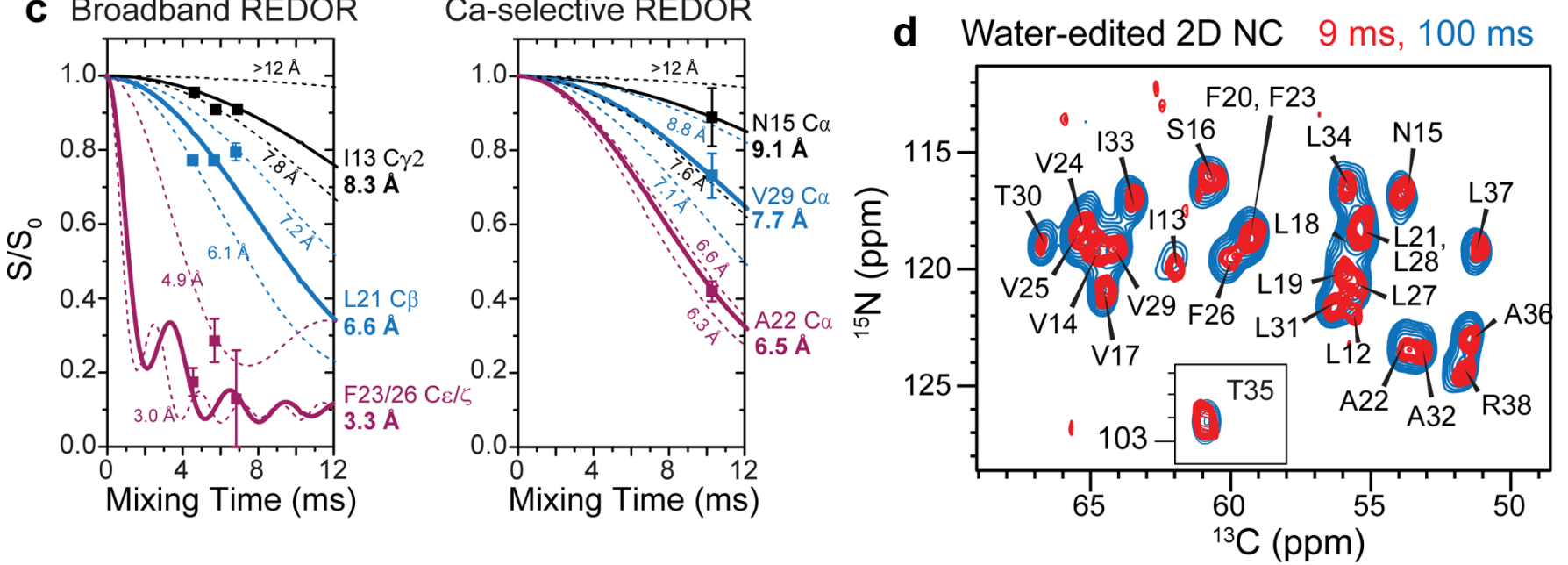

Extended Data Fig. 5 | Additional ${ }^{13} \mathrm{C}-{ }^{-19} \mathrm{~F}$ REDOR spectra and water-edited spectra to determine the interhelical packing of ETM. a, $2 \mathrm{D}{ }^{13} \mathrm{C}-{ }^{13} \mathrm{C}$ correlation spectrum of mixed $4-{ }^{-19} \mathrm{~F}$-Phe labeled and $\mathrm{U}-{ }^{13} \mathrm{C},{ }_{1}^{15} \mathrm{~N}$-labeled ETM (black). The ${ }^{13} \mathrm{C}$ chemical shifts of most residues are similar to the ${ }^{13} \mathrm{C},{ }_{1}^{15} \mathrm{~N}$-labeled protein (red), indicating that fluorination does not perturb the ETM conformation. F20/23 C $\beta$, F26 C $\beta$, and T30 C $\gamma 2$ show small chemical shift changes (blue) of 0.3-0.6 ppm. The spectra were measured at $293 \mathrm{~K} . \mathbf{b}, 1 \mathrm{D}{ }^{13} \mathrm{C}-{ }^{19} \mathrm{~F}$ REDOR control $\left(\mathrm{S}_{0}\right)$, dephased $(\mathrm{S})$, and difference $(\Delta \mathrm{S})$ spectra. The difference peaks result from carbons that are in close proximity to a fluorine in a neighboring helix. The broadband REDOR spectra (left) show both sidechain and backbone ${ }^{13} \mathrm{C}$ signals whereas the $\mathrm{C} \alpha$-selective REDOR spectra (right) detect only $\mathrm{C} \alpha$ signals. c, Representative ${ }^{13} \mathrm{C}-{ }^{19} \mathrm{~F}$ REDOR dephasing curves for broadband and $\mathrm{C} \alpha$-selective C-F REDOR spectra. The $\mathrm{S} / \mathrm{S}_{0}$ values have been corrected for the isotopic dilution factor (50\%) and the peak-overlap factor. Best-fit distance curves are shown as solid lines, and lower and upper distance bounds are shown as dashed lines. Error bars represent random uncertainty of the measured $\mathrm{S} / \mathrm{S}_{0}$ values, which were propagated from the signal-to-noise ratios of the $\mathrm{S}_{0}$ and $\mathrm{S}$ spectra. $\mathbf{d}$, Water-edited $2 \mathrm{D}{ }^{15} \mathrm{~N}-{ }^{13} \mathrm{C} \alpha$ correlation spectra to detect well hydrated residues. The spectra were measured at $293 \mathrm{~K}$ under $11.8 \mathrm{kHz}$ MAS using ${ }^{1} \mathrm{H}-{ }^{1} \mathrm{H}$ mixing times of $9 \mathrm{~ms}$ (red) and $100 \mathrm{~ms}$ (blue). 


\section{a NCACX, $250 \mathrm{~ms}$ CORD}

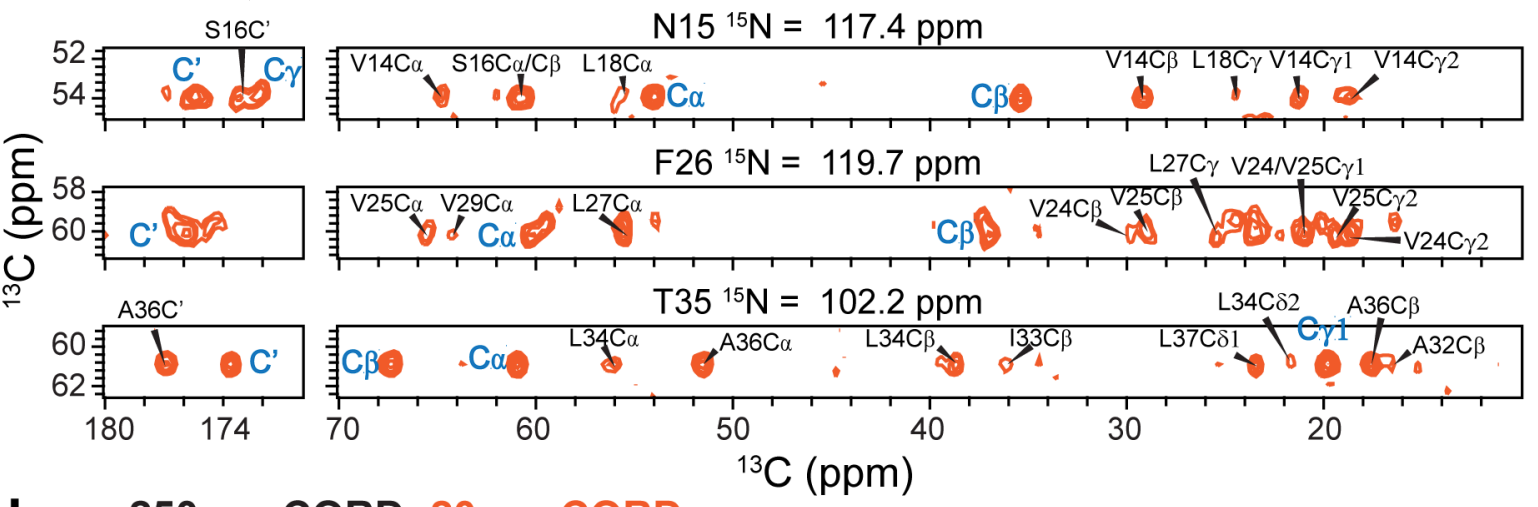

b $250 \mathrm{~ms}$ CORD; $20 \mathrm{~ms}$ CORD
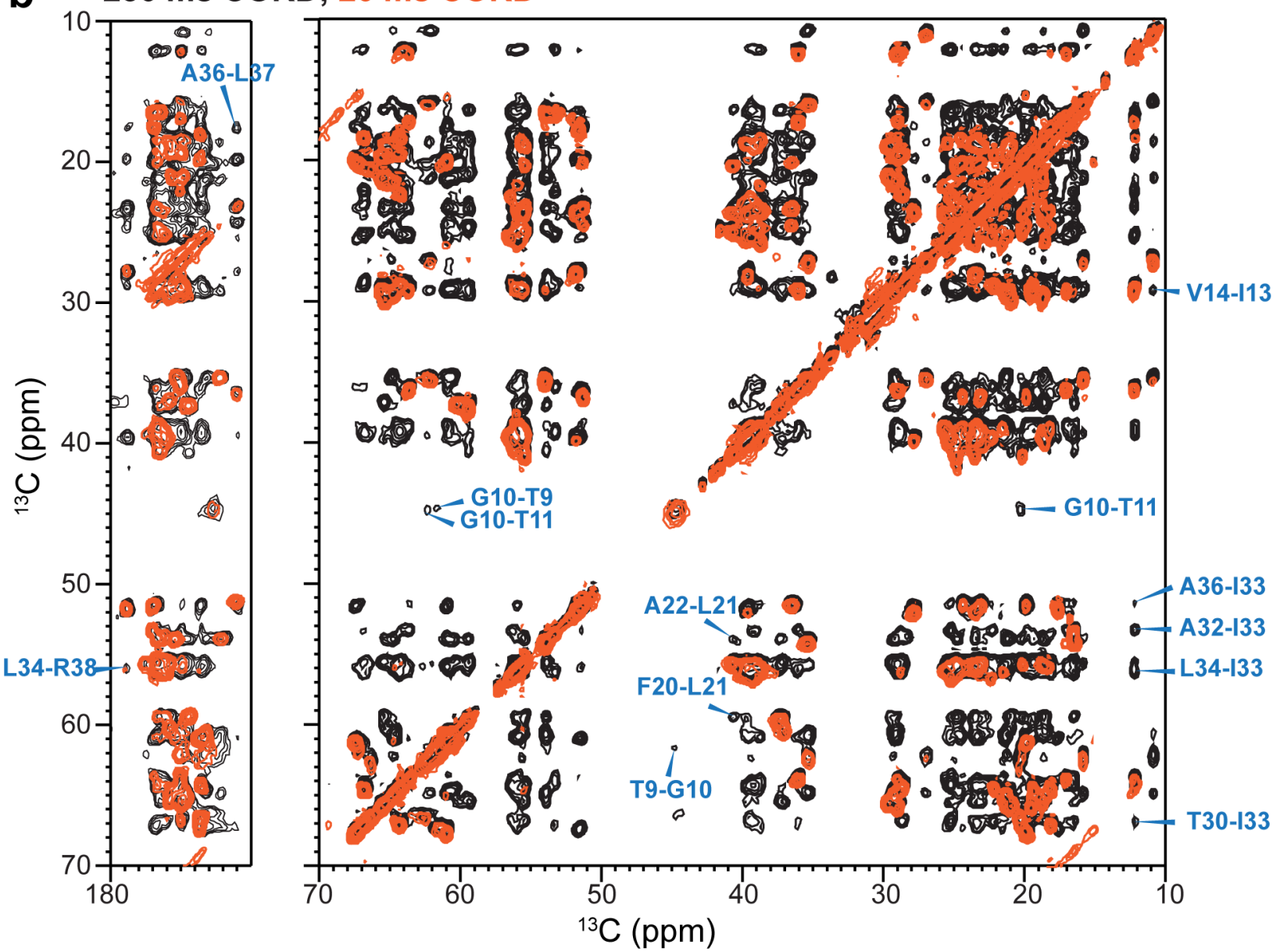

Extended Data Fig. 6 | Inter-residue correlations obtained from $250 \mathrm{~ms} 2 \mathrm{DD}^{13} \mathrm{C}$ spin diffusion spectra of ERGIC-membrane bound ETM. a, Representative strips from a well-resolved 3D NCACX spectrum recorded with $250 \mathrm{~ms}{ }^{13} \mathrm{C}$ spin diffusion. Inter-residue cross peaks are assigned in black and intra-residue resonances are marked in blue. b, Overlay of $2 \mathrm{D}^{13} \mathrm{C}-{ }^{-13} \mathrm{C}$ correlation spectra measured with $250 \mathrm{~ms}$ mixing (black) and $20 \mathrm{~ms}$ (orange). Representative inter-residue cross peaks are assigned in blue. All spectra were measured at $293 \mathrm{~K}$ under $11.8 \mathrm{kHz}$ MAS. 
a

model 1: N15d, no twist

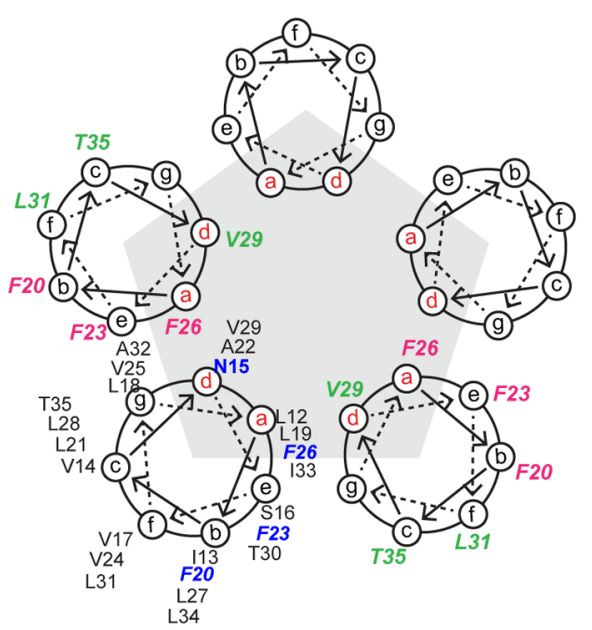

d model 4: N15a, twist: F23b $\rightarrow$ c

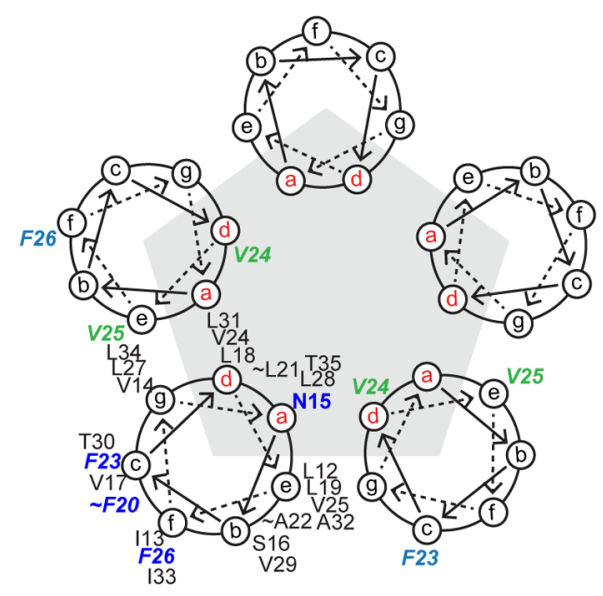

b model 2: N15d, twist: $\mathrm{F} 23 \mathbf{e} \rightarrow \boldsymbol{c}$

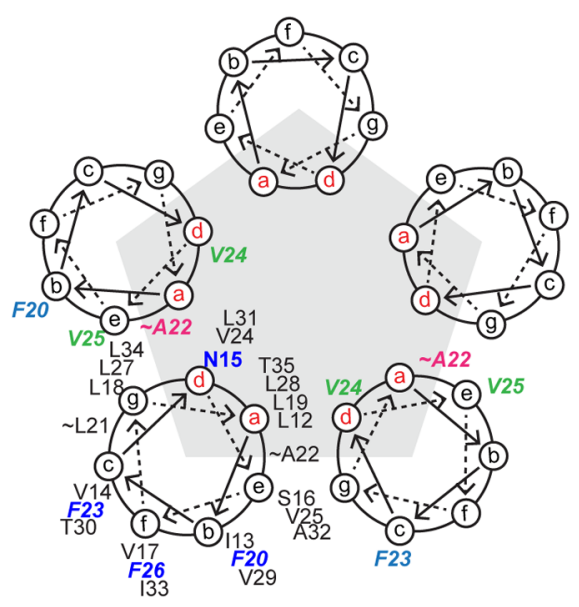

e model 5: N15a, twist: F23b $\rightarrow f$

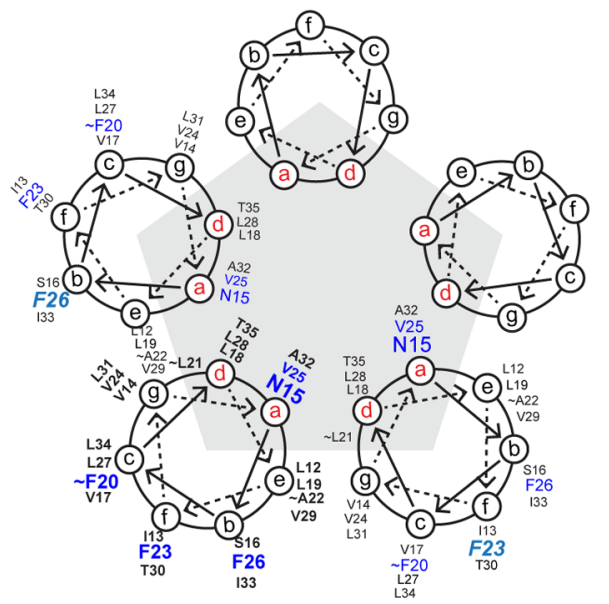

c model 3: N15e, twist: $\mathrm{F} 23 \boldsymbol{f} \rightarrow \boldsymbol{b}$

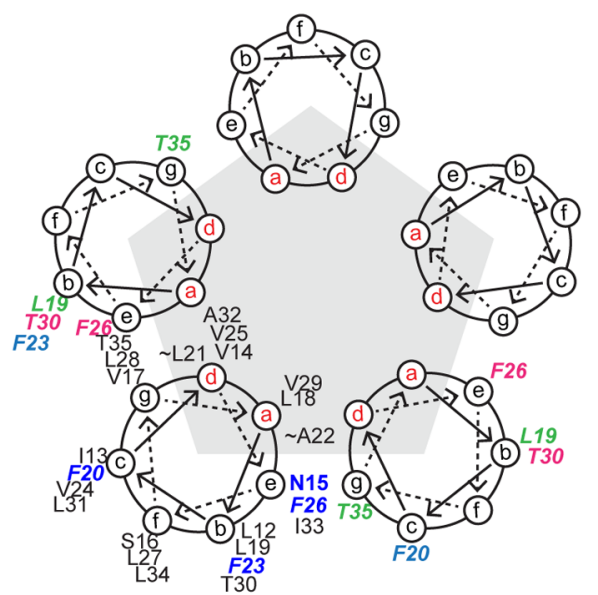

Extended Data Fig. 7 | ETM pentameric models analyzed to disambiguate the direction of interhelical constraints used for structure calculation. For each model, the heptad repeat positions ( $a b c d e f g$ ) of every residue from L12 to T35 is indicated on the helical wheel for at least one subunit. On the two neighboring helices, residue positions that violate measured ${ }^{13} \mathrm{C}-{ }^{19} \mathrm{~F}$ correlations are shown in pink, while residue positions that violate the water and lipid accessibility data are shown in green. The positions of Phe residues that satisfy the interhelical contacts are shown in blue. a, Model 1 places N15 at heptad position $d$ without a twist, and is thus an ideal helix model. b, Model 2 places N15 at $d$ with a twist such that F23 moves from position e to c. c, Model 3 places N15 at position e with a twist such that F23 moves from $f$ to $b$. d, Model 4 places N15 at position $a$ with a twist such that F23 moves from $b$ to $c$. e, Model 5 places N15 at position $a$ with a twist such that F23 moves from $b$ to $f$. Model 5 does not violate any experimental data and was thus chosen to disambiguate intermolecular contacts for structure calculation. To make the interhelical contacts explicit, model 5 shows the residue positions for three consecutive helices in the pentamer. 
a
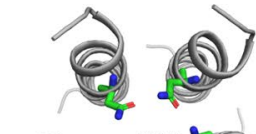

(1) $)^{\mathrm{N} 15}$ (2)

(E)

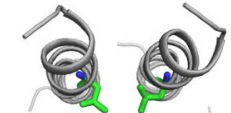

(6)

$(0)$

b

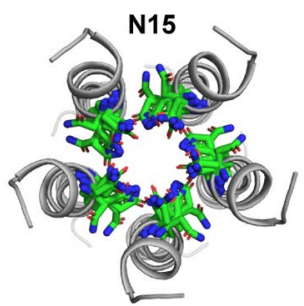

C $E$ in ERGIC bilayers (PDB code: 7K3G)

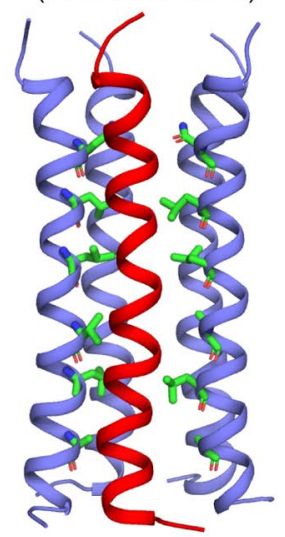

d SARS-CoV-2 E

(PDB code: 7K3G)

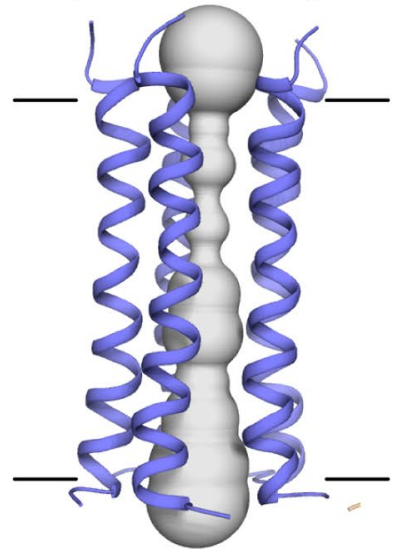

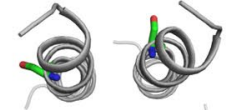

(Q) 16 (2)

D

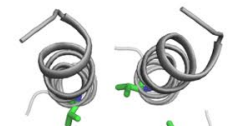

(6) ${ }^{\mathrm{V} 25}$ (2)
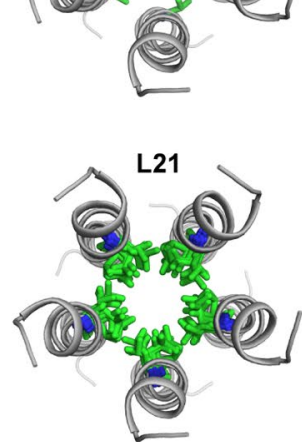

$E$ in LMPG micelles (PDB code: $5 \times 29$ )

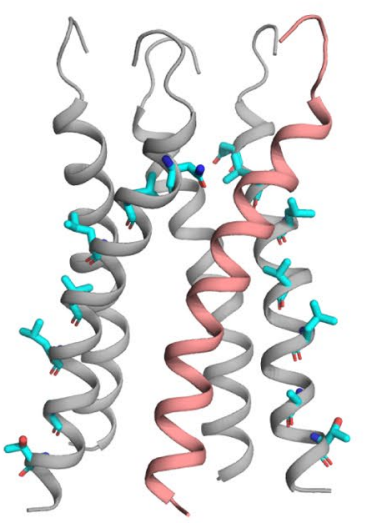

Influenza BM2, Closed (PDB code: 6PVR)

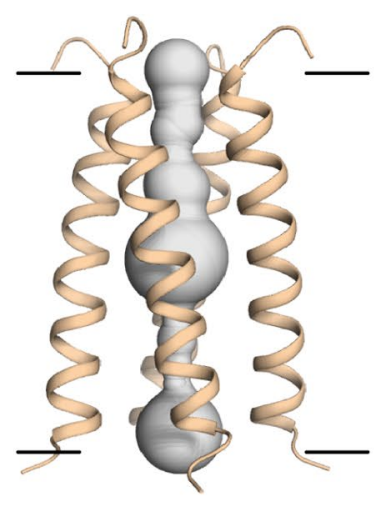

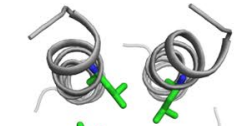
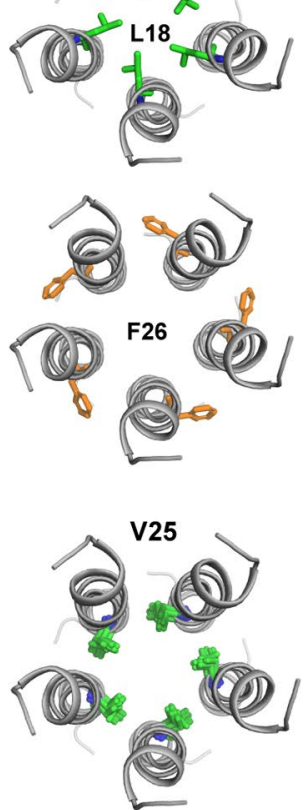

$E$ in ERGIC bilayers (PDB code: $7 \mathrm{~K} 3 \mathrm{G}$ )
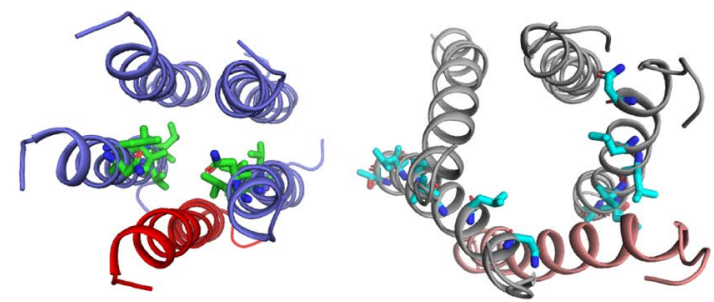

$E$ in LMPG micelles (PDB code: $5 \times 29$ )
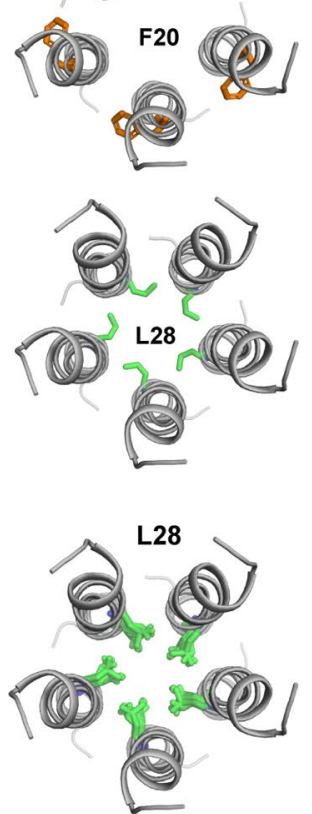
Extended Data Fig. 8 | Lipid-bilayer bound SARS-CoV-2 ETM structure (PDB code: 7K3G) and its comparison with ETM structure solved in micelles and with other viroporin structures. a, N-terminal top views of various residues in the ETM pentamer. Most residues are hydrophobic, including both pore-facing and lipid-facing residues. The most representative structure of the lowest-energy ensemble is shown. $\mathbf{b}$, Top views of representative pore-facing residues in the lowest-energy ensemble. The structure distribution is likely due to a combination of the sparseness of experimental restraints and true protein conformational disorder. c, Comparison of the ERGIC-membrane bound ETM structure model (slate and red) and the LMPG-micelle-bound ETM structure model (gray and salmon) ${ }^{16}$. Side view depicts differences in helix orientation and helical bundle handedness, while top view shows differences in pore radii. d, Structural comparison of the pentameric ETM channel, the closed tetrameric influenza BM2 proton channel ${ }^{25}$, and the pentameric HIV-1 Vpu channel ${ }^{30}$. The ETM pentamer is longer and tighter than the BM2 and Vpu helical bundles. 


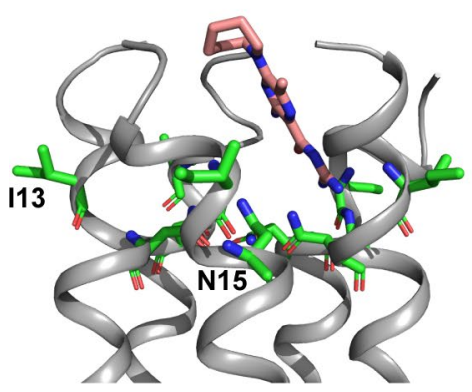

a
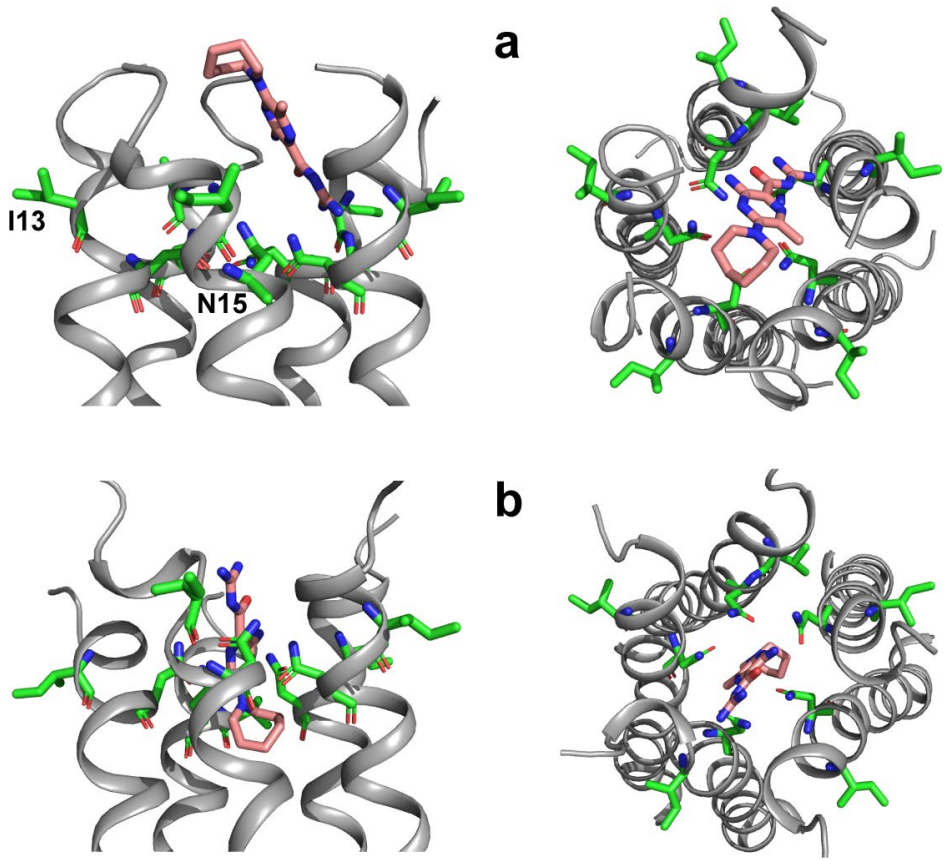

b
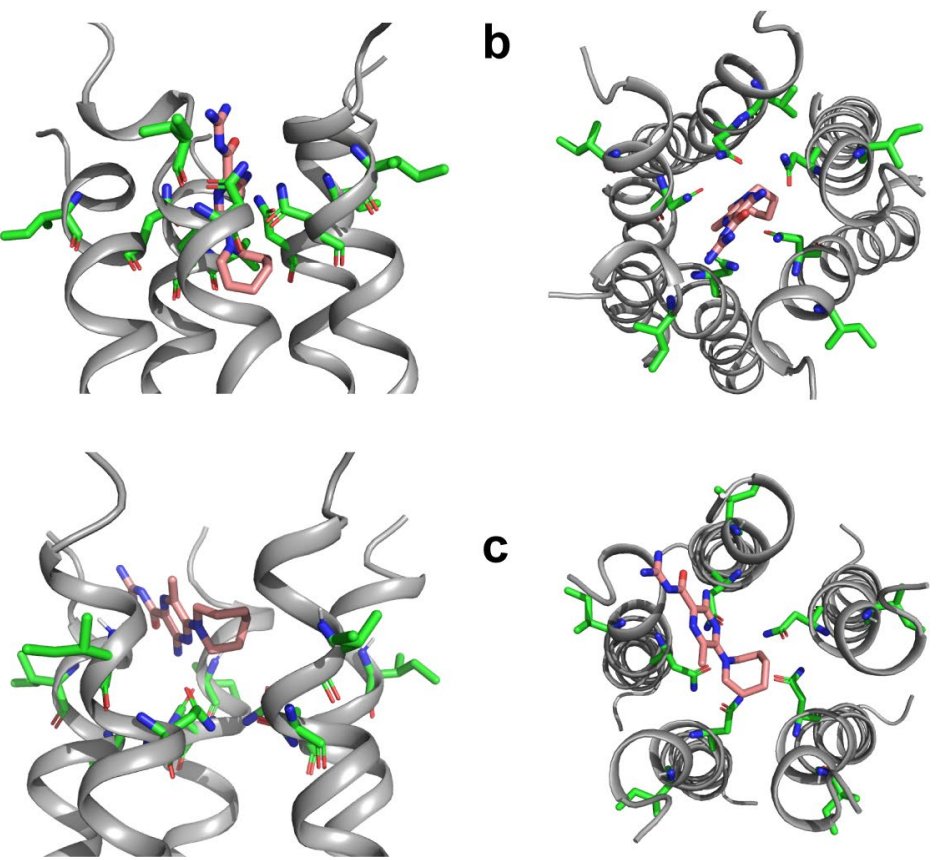

C

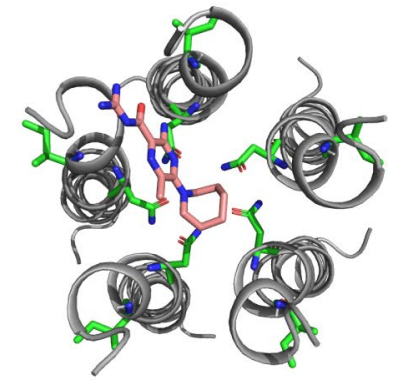

Extended Data Fig. 9 | Additional docking poses of HMA to SARS-CoV-2 E, shown in side view (left) and N-terminal top view (right). a, Structure with hexamethylene ring up and HMA vertical, obtained from docking in DMSO. b. Structure with hexamethylene ring down and HMA vertical, obtained from docking in DMSO. c, Structure with HMA across the channel entrance, bridging two helices, obtained from docking in water. The lipid-facing 113 and pore-occluding N15 are shown in sticks to guide the eye. 

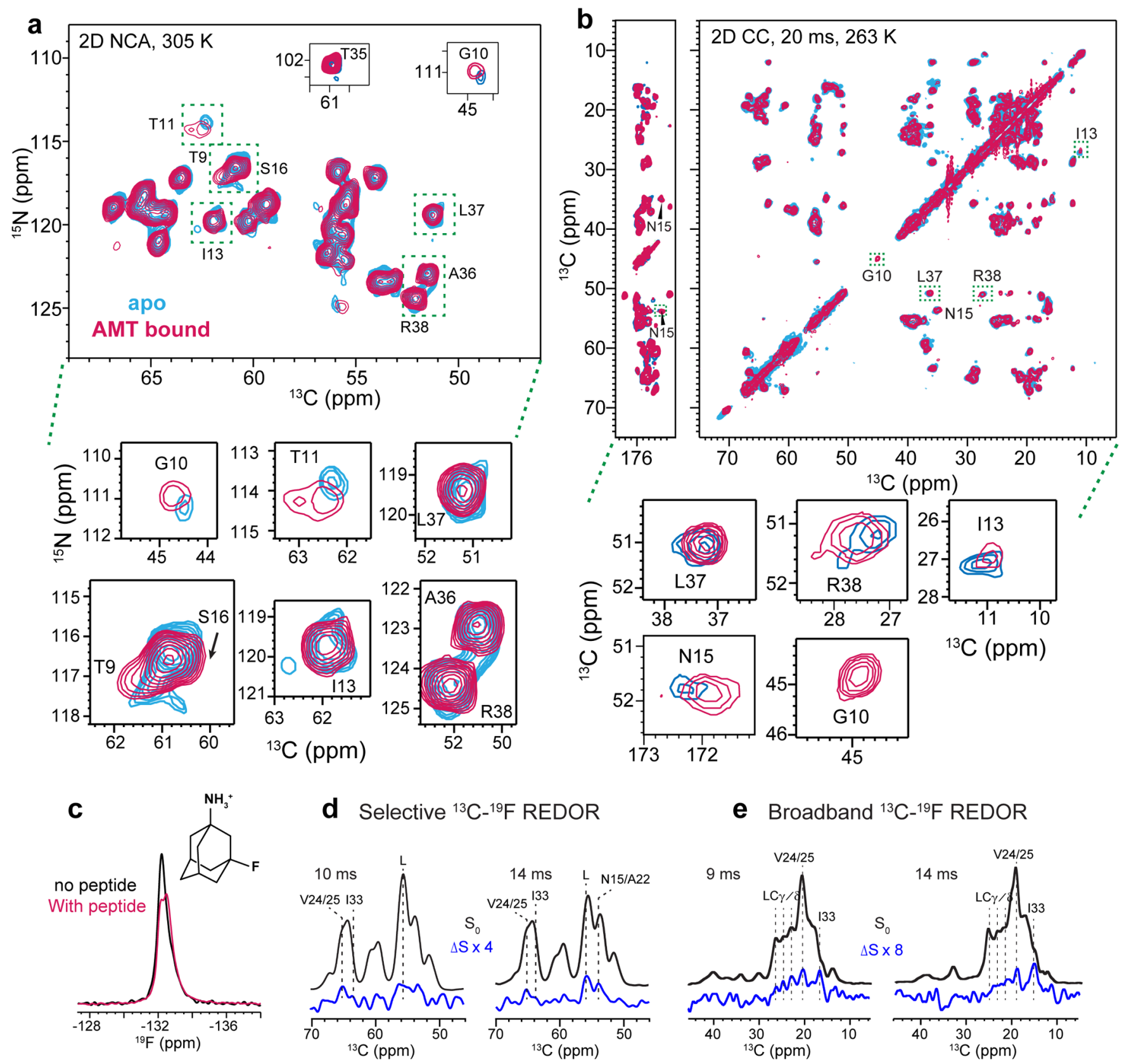

Extended Data Fig. 10 | Effects of amantadine binding on ETM. The peptide is reconstituted in DMPC: DMPG membranes with an AMT: ETM monomer molar ratio of 8: 1. a, 2D ${ }^{15} \mathrm{~N}-{ }^{-13} \mathrm{C} \alpha$ correlation spectra of apo (blue) and AMT-bound ETM (magenta). The spectra were measured at $305 \mathrm{~K}$ under $14 \mathrm{kHz}$ MAS. Zoomed-in areas show peaks with significant CSPs. b, $2 D^{13} \mathrm{C}-{ }^{13} \mathrm{C}$ correlation spectra with $20 \mathrm{~ms}$ mixing of apo (blue) and AMT-bound ETM (magenta). The spectra were measured at $263 \mathrm{~K}$. Zoomed-in areas shows peaks with significant CSPs. The perturbed residues are concentrated in the $\mathrm{N}$ - and $\mathrm{C}$-termini of the protein. $\mathbf{c}, 1 \mathrm{D}^{19} \mathrm{~F}$ direct-polarization spectra of $3 \mathrm{~F}-\mathrm{AMT}$ with and without the peptide in DMPX membranes. The spectra were measured at $270 \mathrm{~K}$ under $14 \mathrm{kHz}$ MAS. d ${ }^{13} \mathrm{C} \alpha$ selective ${ }^{19} \mathrm{~F}$-dephased REDOR spectra of AMT-bound ETM in DMPC: DMPG membranes. The $\triangle \mathrm{S}$ spectra show dephasing at 65.5 ppm, 63.6 ppm, 56 ppm and 54 ppm. e, Broadband ${ }^{13} \mathrm{C}-{ }^{19} \mathrm{~F}$ REDOR spectra. The $\Delta S$ spectra show ${ }^{13} \mathrm{C}$ dephasing for sidechains that belong to residues that show $\mathrm{C} \alpha$ dephasing in (d). 


\section{Reporting Summary}

Nature Research wishes to improve the reproducibility of the work that we publish. This form provides structure for consistency and transparency in reporting. For further information on Nature Research policies, see our Editorial Policies and the Editorial Policy Checklist.

\section{Statistics}

For all statistical analyses, confirm that the following items are present in the figure legend, table legend, main text, or Methods section.

n/a Confirmed

$\bigotimes$ The exact sample size $(n)$ for each experimental group/condition, given as a discrete number and unit of measurement

$\square$ A statement on whether measurements were taken from distinct samples or whether the same sample was measured repeatedly

Х The statistical test(s) used AND whether they are one- or two-sided

Xnly common tests should be described solely by name; describe more complex techniques in the Methods section.

$\triangle \square$ A description of all covariates tested

Х $\square$ A description of any assumptions or corrections, such as tests of normality and adjustment for multiple comparisons

$\checkmark$ A full description of the statistical parameters including central tendency (e.g. means) or other basic estimates (e.g. regression coefficient) AND variation (e.g. standard deviation) or associated estimates of uncertainty (e.g. confidence intervals)

$\triangle$ For null hypothesis testing, the test statistic (e.g. $F, t, r$ ) with confidence intervals, effect sizes, degrees of freedom and $P$ value noted

$\bigotimes \square \begin{aligned} & \text { For null hypothesis testing, the test statistic } \\ & \text { Give } P \text { values as exact values whenever suitable. }\end{aligned}$

Х $\square$ For Bayesian analysis, information on the choice of priors and Markov chain Monte Carlo settings

Х $\square$ For hierarchical and complex designs, identification of the appropriate level for tests and full reporting of outcomes

Х $\square$ Estimates of effect sizes (e.g. Cohen's d, Pearson's $r$ ), indicating how they were calculated

Our web collection on statistics for biologists contains articles on many of the points above.

\section{Software and code}

Policy information about availability of computer code

Data collection NMR data acquisition: Topspin 3.2, 3.6 and 4.0

Data analysis NMR data processing and plotting: Topspin 2.1, 3.2, 3.6 and 4.0

NMR peak picking and resonance assignment: NMRFam Sparky 3

Torsion angle predictions: TALOS-N

Converting experimental restraints to XPLOR-NIH input files: custom code written with Python 3.6

Structure calculation: XPLOR-NIH 2.47 hosted on NMRBox

Data analysis and plotting: Microsoft Excel and OriginPro

13C-19F REDOR simulations: SIMPSON 4.1

13C-19F REDOR fitting: OriginPro

Analysis and Visualization of Reported Structure: Pymol 2.3.4

For manuscripts utilizing custom algorithms or software that are central to the research but not yet described in published literature, software must be made available to editors and

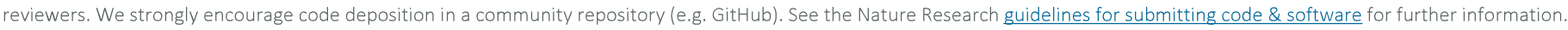


Policy information about availability of data

All manuscripts must include a data availability statement. This statement should provide the following information, where applicable:

- Accession codes, unique identifiers, or web links for publicly available datasets

- A list of figures that have associated raw data

- A description of any restrictions on data availability

NMR chemical shifts, distance and torsion-angle restraints have been deposited in the Biological Magnetic Resonance Bank (BMRB) with ID numbers 30795. The structural coordinates for ETM have been deposited in the Protein Data Bank with accession codes 7K3G.

\section{Field-specific reporting}

Please select the one below that is the best fit for your research. If you are not sure, read the appropriate sections before making your selection.

Х Life sciences

Behavioural \& social sciences

Ecological, evolutionary \& environmental sciences

For a reference copy of the document with all sections, see nature.com/documents/nr-reporting-summary-flat.pdf

\section{Life sciences study design}

All studies must disclose on these points even when the disclosure is negative.

Sample size

Sufficient number of transients or replicates were obtained for each spectrum to generate adequate signal-to-noise.

Data exclusions

No data was excluded.

Replication

Recombinant expression/purification, sample preparation and NMR spectra were highly replicable. Selected isotopically-labeled samples were comprised of multiple batches with reproducible NMR spectra. NMR spectra were reproducible across different blocks of data acquisition.

Randomization

Randomization was not relevant for this study.

Blinding

Blinding was not relevant for this study.

\section{Reporting for specific materials, systems and methods}

We require information from authors about some types of materials, experimental systems and methods used in many studies. Here, indicate whether each material, system or method listed is relevant to your study. If you are not sure if a list item applies to your research, read the appropriate section before selecting a response.

\begin{tabular}{|c|c|}
\hline $\mathrm{n} / \mathrm{a}$ & Involved in the study \\
\hline Х & $\square$ Antibodies \\
\hline$\bigotimes$ & Eukaryotic cell lines \\
\hline Х & Palaeontology and archaeolog \\
\hline Х & $\square$ Animals and other organisms \\
\hline Х & Human research participants \\
\hline Х & Clinical data \\
\hline Х & Dual use research of concern \\
\hline
\end{tabular}
$\mathrm{n} / \mathrm{a}$ Involved in the study

Х $\square$ ChIP-seq

$\triangle \square$ Flow cytometry

Х $\square$ MRI-based neuroimaging 